\title{
FATIGUE STRENGTHENING OF STEEL STRUCTURES USING HIGH MODULUS CFRP PLATES: DEVELOPMENT OF A LIFE-CYCLE ANALYSIS APPROACH
}

\author{
André D. ORCESI ${ }^{1 *}$, Adélaïde FERAILLE ${ }^{2}$ and Sylvain CHATAIGNER ${ }^{3}$
}

\section{Highlights:}

- Unitary data (economic and environmental information) related to fatigue strengthening with high modulus adhesively bonded CFRP solution and additional steel plates is proposed;

- Economic comparison of adhesively bonded high modulus CFRP solution with traditional techniques is carried out;

- Both direct and indirect cost assessments methodologies are settled;

- Life-cycle environmental assessment of high modulus CFRP solution compared to more traditional solutions is also presented.

Keywords: Adhesively bonded CFRP, Strengthening and repair, Steel bridges, Fatigue, LifeCycle Cost, User costs, Life-Cycle Analysis.

\begin{abstract}
With an ageing bridge stock and in order to limit economic and environmental costs, developing preventive maintenance, repair and strengthening strategies will help asset owners to make efficient decisions in a sustainable way. For steel and composite steel bridges, preventing fatigue failure is at stake. In this context, easy-to-apply preventive strengthening techniques should be developed to extend fatigue life-time of steel bridges and delay resource-consuming major interventions such as traditional steel strengthening, rehabilitation, or decommissioning and new construction.
\end{abstract}

\footnotetext{
1* University Paris-Est, IFSTTAR, MAST EMGCU, Marne la Vallée France (corresponding author), e-mail: andre.orcesi@ifsttar.fr.

${ }^{2}$ Université Paris-Est, Laboratoire Navier (UMR 8205), Marne-la-Vallée, France.

${ }^{3}$ IFSTTAR, MAST SMC, Allée des Ponts et Chaussées, Nantes, France.
} 
This paper investigates the cost and environmental assessment of different methodologies used to extend steel bridges fatigue life-time. In particular, one details the needed information and the methodology for the implementation of an overall life-cycle analysis of an adhesively bonded CFRP solution compared with traditional techniques (use of steel plates). This is carried outconsidering economic, environmental and social benefits of the preventing policy and illustrating the developed methodologies using a case study corresponding to the strengthening of an existing steel bridge during its service life.

\section{INTRODUCTION}

Several methods exist to strengthen steel bridges once fatigue issues are suspected. A wellknown solution is the attachment of steel plates to the tension flange of the girders (Figure 1a). This method has however several drawbacks: plates are usually bulky, heavy, difficult to fix and prone to corrosion and fatigue. In addition, it is , labor intensive and may be disruptive to traffic flows, thus limiting their application in the wide network of European and American steel bridges. The use of Carbon Fiber Reinforced Polymers (CFRP) composites (Figure 1b), although more expensive than steel plates in terms of price per unit $/ \mathrm{m} 2$, has several and relevant advantages in comparisons with those more traditional reinforcement methods. Their application is less time consuming than traditional solutions (i.e. from one month to a few days, therefore less traffic disruptive), they have a high strength to weight ratio, excellent fatigue properties, high durability and versatility, and are easy to transport, handle and apply (without heavy equipment) [1], [2].

(a)

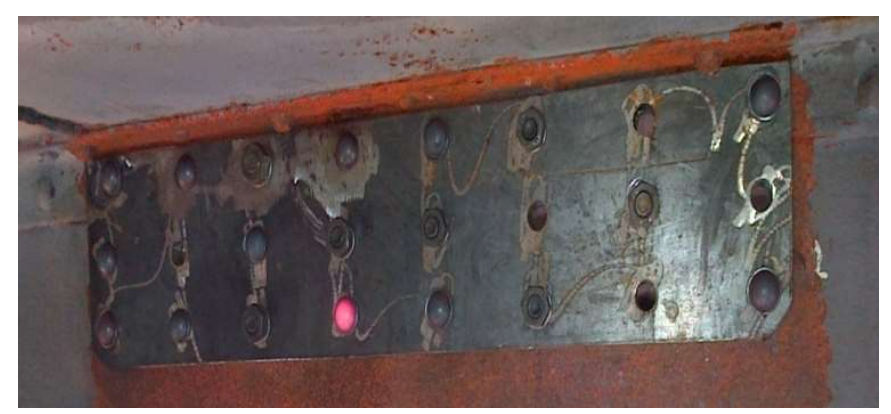

(b)

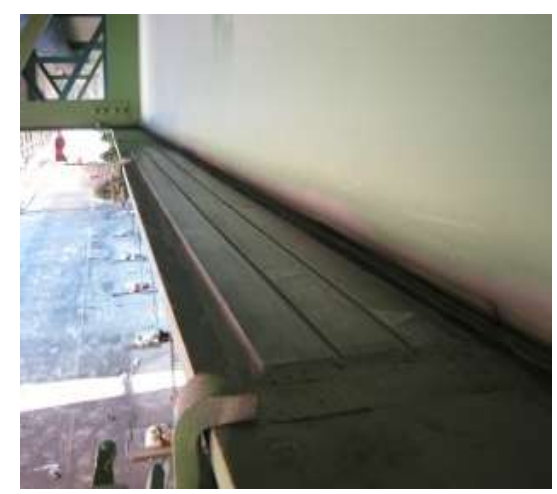

Fig. 1. (a) Additional riveted plate, and (b) Adhesively bonded composite reinforcement. 
Several studies have demonstrated the efficiency of the use of CFRP for strengthening steel structures both as static reinforcement [3], [4] and as fatigue reinforcement before and after crack initiation. In the last case, it may be used as a repair technique to decrease [5], [6] or even stop crack propagation [7]. As far as the application in fatigue before crack initiation is concerned, several studies have demonstrated the efficiency of the technique [8], [9], [10], though only a small number of applications have been documented [11], [12], [13], [14]. If the use of CFRP strips for fatigue strengthening is justified by its optimum mechanical performance, it is required to assess its economical performance taking into account -total costs in terms of the entire execution process as suggested in a report from the National Cooperative Highway Research Program [15]. Among all the elements in this proposed strategic plan to create widespread understanding and application of FRP materials in highway infrastructure, it was thus recommended to perform a study of the relative costs of FRP versus traditional materials. May key issues regarding the use of FRP composites for rehabilitation of steel components in this report were the following ones:

- costs of strengthening deteriorated steel components are mostly labor and societal costs,

- costs of materials in rehabilitation projects does not represent a significant part of the overall cost,

- higher initial costs of FRP composites can be offset by reduced labor, reduced construction time, and reduced traffic disruptions during construction,

- cost-effectiveness of rehabilitation of steel components with FRP composites may be highlighted due to durability of FRP, reductions in construction time and traffic delays. In order to consider these aspects, a life-cycle analysis was introduced to perform the comparison of implementing traditional repair strategies with the use of FRP composites. Not only the material/labor costs and environmental impacts were assessed, but also at the costs associated with traffic disruptions/delays during the repair or retrofit of the bridge. Such analysis was realized in the European project FASSTbridge co-funded by Funding Partners of the ERA-NET Plus Infravation and the European Commission in order to make a link between the variables in the design of the strengthening action, the cost and the final gain on performance and life-time extension [16], [17].

In a first part, the database elaborated in the realm of the project FASSTbridge [18], [19] that is needed for life cycle analyses is presented. The second part is dedicated to the development of a life-cycle cost (LCC) analysis of the developed adhesively bonded CFRP solution [20] aiming at comparing this solution with traditional ones (use of steel plates) and considering the 
economic profit of the preventing policy. The third part is focused on a social analysis to assess user costs for several strengthening options. Finally, the comparison is carried out through a life-cycle analysis (LCA) methodology to assess various environmental impacts associated with each type of strengthening process. In each step of this overall life-cycle analysis, a case study corresponding to the strengthening of an existing steel bridge during its service life is considered for illustration.

\section{INFORMATION USED IN LIFE CYCLE ANALYSES}

\subsection{INPUT DATA}

This section gathers impact information when welding or botlting additional steel plate, or adhesively bonding CFRP (Table 1) to increase the fatigue remaining life of a steel structure. These estimations were based on actual interventions from the partners of FASSTbridge consortium. Breakdown of unit costs are provided in Figure 2 for attachment of steel plates (per $\mathrm{kg}$ of welded or bolted steel plate) and in Figure 3 for adhesively bonded CFRP (per meter of CFRP).

Table 1. Unit data associated with strengthening options.

\begin{tabular}{|c|c|c|c|c|c|}
\hline Item & Unit & Quantity & Ecoinvent Process & $\begin{array}{c}\text { Unitary Cost } \\
(\epsilon)\end{array}$ & $\begin{array}{c}\text { Cost } \\
(\boldsymbol{\epsilon})\end{array}$ \\
\hline \multicolumn{6}{|c|}{ Steel S275JR, welded structure (1 kg) } \\
\hline Workmanship & $\mathrm{h}$ & 0.018 & & 18.96 & 0.34 \\
\hline Workmanship (auxiliary) & $\mathrm{h}$ & 0.018 & & 17.83 & 0.32 \\
\hline Qualified welders & $\mathrm{h}$ & 0.018 & & 24.5 & 0.44 \\
\hline Laminated steel S275 JR & $\mathrm{kg}$ & 1.05 & $\begin{array}{l}\text { steel. low-alloyed. hot } \\
\text { rolled }\end{array}$ & 0.99 & 1.04 \\
\hline Electrolytic coating & 1 & 0.01 & Zinc coating & 7.59 & 0.08 \\
\hline Crane $30 \mathrm{~m}$. span. $750 \mathrm{~kg}$ capacity & $\mathrm{h}$ & 0.005 & & 18.92 & 0.09 \\
\hline Diesel Welder & $\mathrm{h}$ & 0.018 & $\begin{array}{l}\text { Diesel burned in building } \\
\text { machine }\end{array}$ & 3.62 & 0.07 \\
\hline Fungible material & $\%$ & 0.019 & & 5 & 0.1 \\
\hline \multicolumn{6}{|c|}{ Steel S275JR, Bolted structure (1 kg) } \\
\hline Workmanship & $\mathrm{h}$ & 0.028 & & 18.96 & 0.53 \\
\hline Workmanship (auxiliary) & $\mathrm{h}$ & 0.028 & & 17.83 & 0.5 \\
\hline Laminated steel S275 JR & $\mathrm{kg}$ & 1.05 & $\begin{array}{l}\text { steel, low-alloyed, hot } \\
\text { rolled }\end{array}$ & 0.99 & 1.04 \\
\hline Electrolytic coating & 1 & 0.01 & Zinc coating & 7.59 & 0.08 \\
\hline
\end{tabular}




\begin{tabular}{|c|c|c|c|c|c|}
\hline Crane $30 \mathrm{~m}$. span. $750 \mathrm{~kg}$ capacity & $\mathrm{h}$ & 0.01 & $\begin{array}{l}\text { Diesel burned in building } \\
\text { machine }\end{array}$ & 18.92 & 0.19 \\
\hline Fungible material & $\%$ & 0.023 & & 5 & 0.12 \\
\hline \multicolumn{6}{|c|}{ Adhesively bonded CFRP laminate strengthening (1 m) } \\
\hline Resin & $\mathrm{kg}$ & 0.048 & $\begin{array}{l}\text { epoxy resin production. } \\
\text { liquid }\end{array}$ & 23.87 & 1.15 \\
\hline Hardener & $\mathrm{kg}$ & 0.374 & $\begin{array}{l}\text { epoxy resin production. } \\
\text { liquid }\end{array}$ & 9.63 & 3.6 \\
\hline CFRP (460 GPa) & $\mathrm{m}$ & 1.1 & $\begin{array}{l}\text { "home made » CFRP } \\
\text { process } 2\end{array}$ & 200 & 220 \\
\hline $\begin{array}{c}\text { complementary material and } \\
\text { special pieces }\end{array}$ & $\%$ & 0.306 & & 2 & 0.61 \\
\hline Electrogen group INS $40 \mathrm{KVAs}$ & $\mathrm{h}$ & 0.03 & $\begin{array}{l}\text { Diesel burned in building } \\
\text { machine }\end{array}$ & 4.52 & 0.14 \\
\hline Sander & $\mathrm{h}$ & 0.2 & $\begin{array}{l}\text { Diesel burned in building } \\
\text { machine }\end{array}$ & 4.75 & 0.95 \\
\hline Crew Type B & $\mathrm{h}$ & 0.2 & & 36.86 & 7.37 \\
\hline
\end{tabular}

(a)

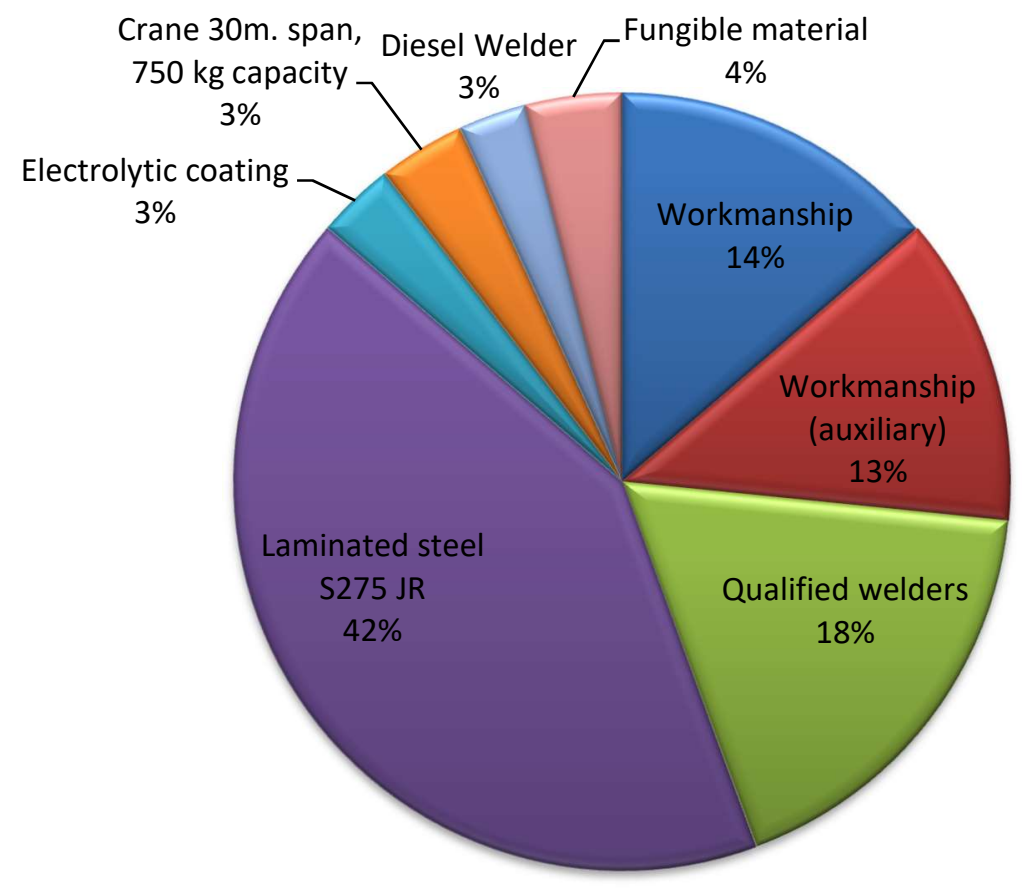

(b) 


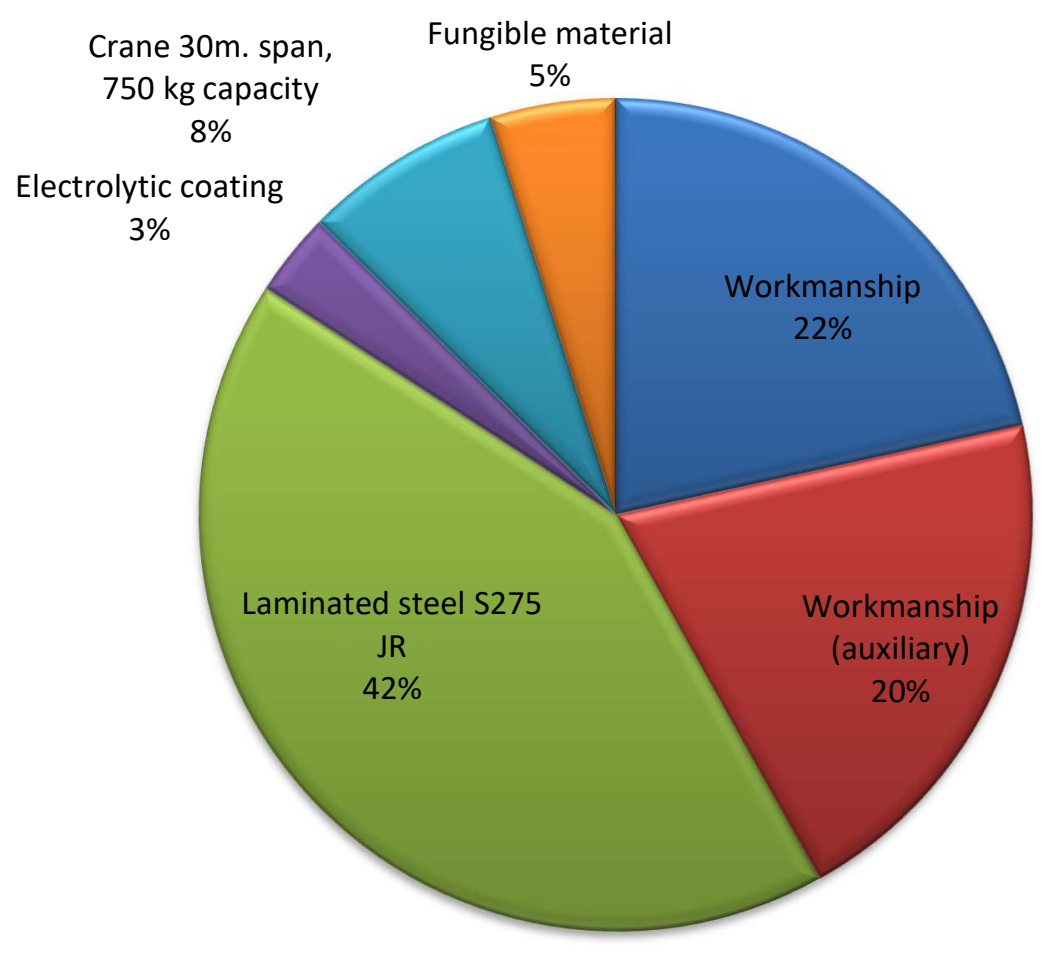

Fig. 2. Breakdown of costs for (a) welded and (b) bolted steel plates.

(a)

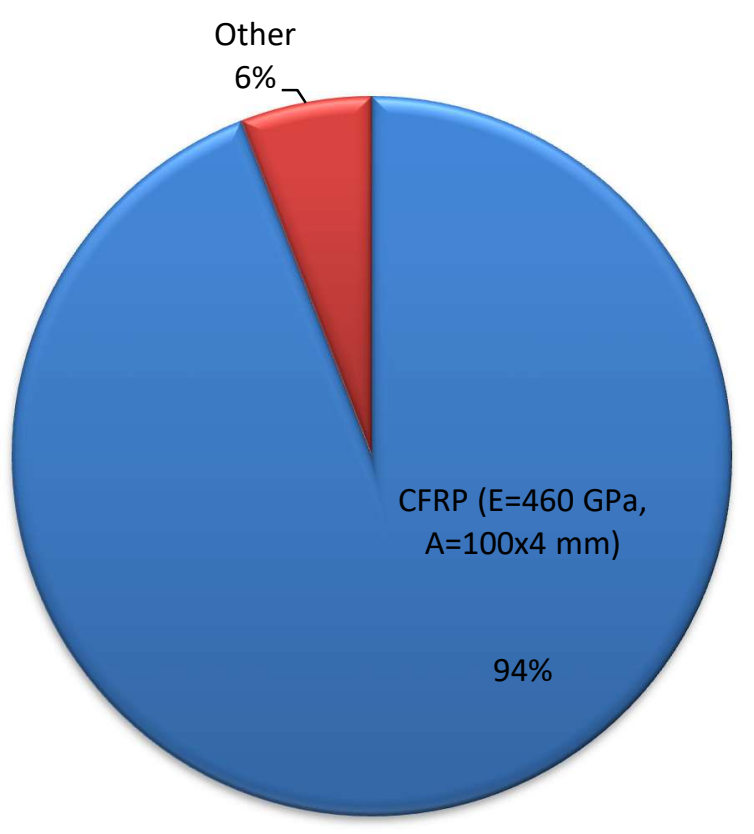

(b) 


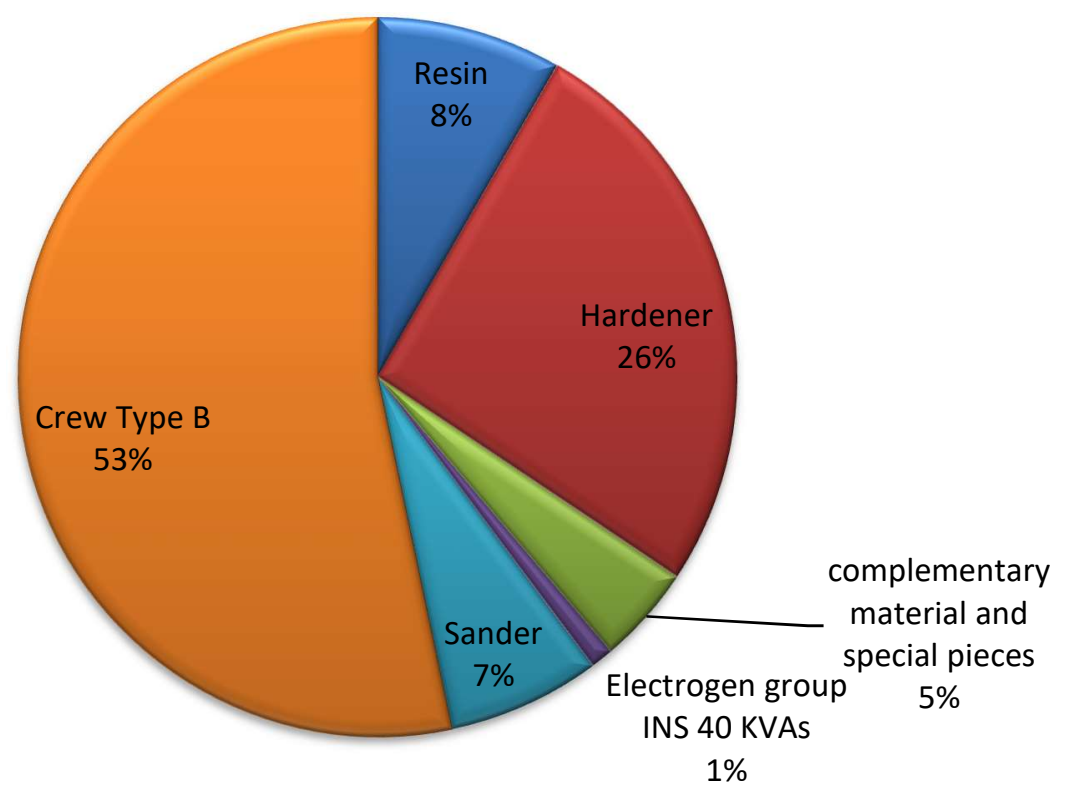

Fig. 3. (a) Breakdown of costs for CFRP solution and (b) detail of other costs (except CFRP laminates).

The unitary cost of material is clearly higher for adhesively bonded CFRP than for steel plates (welded or bolted), which is mainly due to the cost of CFRP laminates (94\% of the cost, as shown in Fig. 3a). However, in terms of the entire execution process, such solution might be cost-effective t. The swiftness of the intervention, compared to the traditional attachment of steel plates can indeed reduce the costs of auxiliary means (platform, scaffolds), making easier the transport (steel plates are heavy and difficult to handle in the worksite) and the labour (welding requires qualified and experienced workers). Nevertheless, it is highlighted that the surface preparation of the steel, prior to bonding CFRP, has an important influence on the longterm behaviour of the steel-to-CFRP bonded joints. The surface preparation process and in particular the blasting process are very important for bonded systems and might take time and cost. Preliminar studies in the project FASSTBRIDGE focused on the surface preparation choice. Sandblasting was adopted and the durability of the assembly assessed through extensive investigations [20].

To the unit costs in Table 1 are then added the scaffolding and rental equipment costs such as forklift in work site, when necessary (Table 2).

Table 2. Additional costs.

\begin{tabular}{|c|c|c|c|c|}
\hline Item & Description & $\begin{array}{l}\text { Welded } \\
\text { solution }\end{array}$ & $\begin{array}{l}\text { Bolted } \\
\text { solution }\end{array}$ & $\begin{array}{l}\text { Adhesively bonded } \\
\text { CFRP }\end{array}$ \\
\hline $\begin{array}{l}\text { Scaffold and platforms } \\
(€ / \mathrm{m} 2)\end{array}$ & $\begin{array}{l}\text { Rental equipment - } \\
400 € / \text { day }\end{array}$ & 4800 & 4800 & 2000 \\
\hline
\end{tabular}




$\begin{array}{llllc} & \begin{array}{l}\text { Installation }+ \\ \text { dismantling }\end{array} & 350 & 350 & 350 \\ & \text { Installation certificate } & 300 & 300 & 300 \\ & \text { Transport } & 400 & 400 & 400 \\ \text { Forklift in work site }(€) & \begin{array}{l}\text { Rental equipment - } \\ \text { 80€/day }\end{array} & 960 & 960 & - \\ & \text { Transport } & 1200 & 1200 & -\end{array}$

The average work duration for such a strengthening project is assessed to be around 12 days for welded and bolted solutions and 5 days for CFRP. It can be noted that there is no forklift location in work site when using CFRP. The difference in duration of works can be explained by the higher production rate with CFRP than the one for a structural steel welded or bolted solution. In particular in the case of the welded solution, one should include the number of hours needed for installation, surface preparation apart, including plates preparation, plates presentation, plates pre-fixation and welding. In addition, an inspection (the day after) of the welds would be necessary (non-destructive, such as magnetic particle or ultra-sound) and could imply the need for some reparation works (quite common when welding onsite). As a conclusion, steel welded solution could be between two to three times slower than CFRP solution [21]. Besides, welding steel plates to the existing steel structures produce heat affected zones (HAZ), which generally creates some residual tensile stresses that make the joint susceptible to fatigue cracking. Providing alternatives to such process is then an important field of research!

\subsection{PERFORMANCE ANALYSIS}

The remaining fatigue life time of the studied structure is assessed herein according to the regulation of Eurocode EN 1993-1-9 7.1 (3) [22]. For nominal stress spectra with stress ranges above and below the constant amplitude fatigue limit $\Delta \sigma_{D}$ (for 5 million cycles according to Eurocode EN 1993-1-9 7.1 (3)), the fatigue strength is based on the extended fatigue strength curve as follows:

$$
\begin{gathered}
N_{R}=\frac{\Delta \sigma_{c}^{m} \times 2.10^{6}}{\Delta \sigma_{R}^{m}} \text { with } m=3 \text { for } N \leq 5.10^{6} \\
N_{R}=\frac{\Delta \sigma_{D}^{m} \times 5.10^{6}}{\Delta \sigma_{R}^{m}} \text { with } m=5 \text { for } 5.10^{6}<N \leq 1.10^{8}
\end{gathered}
$$

$\mathrm{N}_{\mathrm{R}}$ being the number of cycles, $\Delta \sigma_{R}$ the direct stress range, and $\Delta \sigma_{c}$ the detail category $[22]$. 
The fatigue detail category 50 (reference value $\Delta \sigma_{C}=50 \mathrm{~N} / \mathrm{mm}^{2}$ for the fatigue strength at 2 million cycles) is considered for illustration in the following. The steel section properties and fatigue design life configuration are provided in Table 3. To simplify the illustration of the methodology, the strengthening project is based on this fatigue assessment configuration, that can be extended to the scale of the structure.

Table 3. Properties of steel section and axial stress considered for illustration.

\section{Cross section}

Thickness $t=35 \mathrm{~mm}$ Width $b=550 \mathrm{~mm}$ $A=19,250 \mathrm{~mm}^{2}$

Axial stress

$\begin{array}{llll} & \text { If stress relieved } & \text { If not stress relieved } & \\ \sigma_{\max }=30.5 \mathrm{~N} / \mathrm{mm}^{2} & \Delta \sigma_{R}=\left|\sigma_{\max }\right|+0.6\left|\sigma_{\min }\right| & \Delta \sigma_{R}=\left|\sigma_{\max }\right|+\left|\sigma_{\min }\right| & \Delta \sigma_{C}=50 \mathrm{~N} / \mathrm{mm}^{2} \\ \sigma_{\min }=-5.6 \mathrm{~N} / \mathrm{mm}^{2} & \Delta \sigma_{R}=33.86 \mathrm{~N} / \mathrm{mm}^{2} & \Delta \sigma_{R}=36.1 \mathrm{~N} / \mathrm{mm}^{2} & \Delta \sigma_{D}=36.85 \mathrm{~N} / \mathrm{mm}^{2} \\ & \Delta \sigma^{2} & \end{array}$

For a real application, the proposed approach should be applied to the whole structure (taking into account all the most critical fatigue details), and a specific initial work should be carried out to assess the remaining fatigue life of the studied structure on the basis of regulatory load design recommendations, or on site measurement in terms of traffic for instance. The service life increase is then obtained through the addition of cross-sectional material that decreases stress for the studied detail [12]. The validity of this assumption was verified through preliminar laboratory investigations especially considering fatigue issues [20]. Three options are taken into account for fatigue service life increase:

- additional welded steel plates,

- additionel bolted steel plates,

- adhesively bonded CFRP plate.

In order to make a comparison based on the equivalent performance, the solutions are compared keeping the rigidity constant (product of the Young modulus (E) by the cross-section). The obtained characteristics associated with each of the three solutions are provided in Table 4. $\mathrm{n}$ corresponds to the number of applied reinforcement plates, a to the width of the plate, $b$ to its thickness, and $\mathrm{E}$ to the axial modulus of the material used as reinforcement. Al corresponds to the additional reinforcement cross-section (n.a.b), and Al/A corresponds to the percentage of additional cross-section. This allows obtaining the stress reduction $(1 /(1+\mathrm{Al} / \mathrm{A}))$, and consequently the design life increase using Equations (1) and (2). 
Table 4. Cost $/ \mathrm{m}$ for several design life increase configurations.

\begin{tabular}{|c|c|c|c|c|c|c|c|c|c|c|c|}
\hline $\mathbf{n}$ & $\mathbf{a}$ & b & $\mathbf{E}$ & Al & $\mathbf{A} \mathbf{l} / \mathbf{A}$ & $\begin{array}{l}\text { Stress } \\
\text { reduction }\end{array}$ & $\begin{array}{l}\text { Stress } \\
\text { range }\end{array}$ & $\begin{array}{l}\text { Design } \\
\text { life }\end{array}$ & $\begin{array}{l}\text { Design life } \\
\text { increase }\end{array}$ & Weight & Cost $/ m$ \\
\hline & $\mathrm{mm}$ & $\mathrm{mm}$ & GPa & $\mathrm{mm}^{2}$ & & & $\mathrm{~N} / \mathrm{mm}^{2}$ & & & $\mathrm{Kg}$ & $€$ \\
\hline \multicolumn{12}{|c|}{ Steel S275JR, welded structure } \\
\hline 1 & 145 & 6 & 210 & 870.00 & 0.05 & 0.96 & 32.4 & $7,353,107$ & 1.14 & 6.7 & 13.7 \\
\hline 2 & 145 & 6 & 210 & 1740.00 & 0.09 & 0.92 & 31.1 & $8,348,804$ & 1.30 & 13.4 & 27.3 \\
\hline 3 & 145 & 6 & 210 & 2610.00 & 0.14 & 0.88 & 29.8 & $9,430,559$ & 1.46 & 20.1 & 41.0 \\
\hline \multicolumn{12}{|c|}{ Steel S275JR, bolted structure } \\
\hline 1 & 145 & 6 & 210 & 870.00 & 0.05 & 0.96 & 32.4 & $7,353,107$ & 1.14 & 6.7 & 16.5 \\
\hline 2 & 145 & 6 & 210 & 1740.00 & 0.09 & 0.92 & 31.1 & $8,348,804$ & 1.30 & 13.4 & 33.0 \\
\hline 3 & 145 & 6 & 210 & 2610.00 & 0.14 & 0.88 & 29.8 & $9,430,559$ & 1.46 & 20.1 & 49.4 \\
\hline \multicolumn{12}{|c|}{ Adhesively bonded CFRP } \\
\hline 1 & 100 & 4 & 460 & 876.19 & 0.05 & 0.96 & 32.4 & $7,359,896$ & 1.14 & 0.81 & 233.8 \\
\hline 2 & 100 & 4 & 460 & 1752.38 & 0.09 & 0.92 & 31.1 & $8,363,586$ & 1.30 & 1.62 & 466.7 \\
\hline 3 & 100 & 4 & 460 & 2628.57 & 0.14 & 0.88 & 29.8 & $9,454,615$ & 1.47 & 2.42 & 699.5 \\
\hline
\end{tabular}

In particular, one can see in Table 4 that adhesively bonded CFRP introduces a significantly lower additional weight to the existing bridge structure compared to additional steel plates.

As already mentioned, the additional costs due to the scaffold and platform rent, installation/dismantling, transport, and to the use of forklift in work sites (see Table 2) need to be added to these costs detailed in Table 4 .

One significant assumption in the following is that only fatigue phenomena influence the end of life time. Serviceability and ultimate limit states are therefore not considered to be reached first for the sake of simplicity in the analysis and to highlight (i) the benefit of strengthening actions when compared to a "Do Nothing" strategy, and (ii) the benefit of CFRP solution when compared to traditional maintenance strategies.

\section{ECONOMIC ANALYSIS}

\subsection{LIFE-CYCLE COST FRAMEWORK}

The unit costs provided previously are considered herein to compute the life-cycle analysis including the cost of the strengthening action for the bridge owner and the corresponding impact on the effective year for decommissioning/reconstruction.

The costs included in a life-cycle analysis occurring at varying points in time, there is a need to convert them into a value at a common point in time. The net present value approach which 
directly applies discount factors to each year projected cash flow is one of the most used methods to compare past and future cash flows with those of today. To make costs timeequivalent, the approach discounts them to a common point in time, the discount rate of money reflecting the investor's opportunity costs of money over time. The value of the yearly discount rate used is crucial since the current worth of money (NPV) is highly sensitive to this parameter [23] [24]. Indeed, the higher the discount rate, the more importance is given to the near-present. Choosing a high discount rate may then promote management strategies with low initial costs and a costly end-of-life. Therefore, the choice of the discount rate is delicate and has to be in agreement with the time horizon.

Some assumptions on the proposed case study are provided in Table 5.

Table 5. Parameters considered in the economic analysis.

\begin{tabular}{|c|c|c|}
\hline Item & Description & Value \\
\hline$r$ & Discount rate & $2 \%$ \\
\hline$T_{f}^{0}$ & Initial end of the service life & 100 yrs. \\
\hline$A_{b}$ & Area of the bridge deck $\left(\mathrm{m}^{2}\right)$ & $1,093 \mathrm{~m}^{2}$ \\
\hline$T_{S}$ & Year of strengthening action & Between year 50 and 100 \\
\hline$G_{S}$ & Gain of fatigue service life & $14 \% / 30 \% / 46 \%$ \\
\hline$c_{S, u}^{j, i}$ & $\begin{array}{c}\text { Unit cost for strengthening solution } j \\
\text { and gain type } i \text { (welded/bolted steel } \\
\text { plates or CFRP) }\end{array}$ & $\begin{array}{l}\text { See Table } 4 \text { for each } \\
\text { value of } G_{S}\end{array}$ \\
\hline$C_{w}^{j}$ & $\begin{array}{l}\text { Additional costs for scaffolding and } \\
\text { forklift location for solution } j\end{array}$ & See Table 2 \\
\hline$A_{S C}$ & $\begin{array}{l}\text { Moving area of bridge deck with } \\
\text { scaffolding }\end{array}$ & $10 \mathrm{~m}^{2}$ \\
\hline$C_{f}$ & $\begin{array}{l}\text { Unit decommissioning-reconstruction } \\
\qquad \text { costs }\end{array}$ & $100-700 € / \mathrm{m}^{2}$ \\
\hline$L_{S}$ & Length of strengthening area & $50-100-150 \mathrm{~m}$ \\
\hline
\end{tabular}

The strengthening action is assumed to be performed between year $T_{S, 0}=50$ and the initial end of the service life $T_{f}^{0}$. The increase of remaining fatigue life is calculated each time by applying 
the considered gain to the effective remaining fatigue service life $\left(T_{f}-T_{S}\right)$. Consequently, the later the maintenance project is conducted, the lower the increase of residual life is as more and more fatigue potential resistance is already consumed. To be realistic, the calculation of the updated residual fatigue life should be based on the effective number of cycles, considering the traffic volume. Assuming a distribution of 11,900 vehicles per day with $1.5 \%$ of trucks, configuration in Table 3 enables to reach an initial 100-year service life before strengthening. A gain $G_{S}=14 \%$ or $30 \%$ or $46 \%$ for residual fatigue service life is then considered each time ( $G_{S}$ corresponds to the number $n$ of reinforcement layers applied, see Table 4) and associated with an updated end of service life $T_{f}^{1}, T_{f}^{2}$ and $T_{f}^{3}$, respectively. Finally, three cases are considered for the length of strengthening area $L_{S}$. Obviously, the higher $L_{S}$ and $G_{S}$, the larger the difference of direct material costs between welded/bolted steel plates and adhesively bonded CFRP, knowing the cost per meter of these solutions (see Table 4). Considering the potential savings in additional costs (Table 2) for the CFRP solution, the question is to identify when each strengthening option is more interesting than the others from an economic point of view, also considering a "Do Nothing" strategy.

The proposed methodology assesses the $N P V$ at $T_{S, 0}$ of all future costs including strengthening ones that can occur at different years. Doing this, the "Do Nothing" strategy (DN) is characterized only by the discounted decommissioning/reconstruction costs assumed to occur at $T_{f}^{0}$ (year 100 in this example):

$$
N P V_{0}\left(T_{S}\right)=\frac{C_{f}}{(1+r)^{T_{f}^{0}-T_{S, 0}}}
$$

The alternative strategies with some strengthening actions (use of welded or bolted steel plates or use of adhesively bonded CFRP) are applied at $T_{S, 0} \leq T_{S} \leq T_{f}^{0}$ and associated cost is added to the end of life costs which occur at $T_{f}^{1}\left(T_{S}\right), T_{f}^{2}\left(T_{S}\right), T_{f}^{3}\left(T_{S}\right) \geq T_{f}^{0}$ in case of maintenance (when $G_{S}=14 \%$ or $30 \%$ or $46 \%$, respectively) since the residual fatigue remaining life is increased. The effect is clearly dependent on $G_{S}$ and on the effective year of strengthening action (as the gain is always calculated on the remaining fatigue lifetime at $T_{S}, T_{f}^{i}$ decreases 
with $T_{S}$ ). The total cost for each type of repair project can be calculated with information previously provided on unit $\operatorname{cost} c_{S, u}^{j, i}$, additional cost $C_{w}^{j}$ and length $L_{S}$ of strengthening. The net present value at $T_{S, 0}$ for strengthening solution $j$ and gain of fatigue service life $i$ applied at year $T_{S}$ can be obtained as follows:

$$
N P V_{j, i}\left(T_{s}\right)=\frac{C_{f}}{(1+r)^{T_{f}^{i}\left(T_{s}\right)-T_{s, 0}}}+\frac{c_{s, u}^{j, i} \times L_{S}+C_{w}^{j}}{(1+r)^{T_{s}-T_{s, 0}}} \text { with } T_{S, 0} \leq T_{S} \leq T_{f}^{0}
$$

Such an approach reflects a decision making process where one investigates at a specific year (here $T_{S, 0}$ ) the interest to postpone some strengthening action and to find the optimal year of application in the future. In this approach, $T_{S, 0} \leq T_{S} \leq T_{f}^{0}$ but the decision is always considered at year $T_{S, 0}$.

Figure 4 focuses on the logic attached to the comparison between different options (as noted previously, $c_{S, u}^{j, i}$ and $C_{w}^{j}$ do not vary in the same way from one option to another). Parameters detailed in Table 5 will orientate the strategy between delaying or anticipating an intervention. In particular, the gain $G_{S}$ relies on the number of layers of materials, which governs $c_{S, u}^{j, i}$, then $c_{S, u}^{j, i} \times L_{S}$ in Equation 4. In Figure 4, the length of strengthening area is fixed at $50 \mathrm{~m}$.

Figure 4a illustrates the cost $N P V_{j, 1}$ obtained with different options $(j=1,2,3$ for welded, bolted steel plates and adhesively bonded CFRP, respectively), with $G_{S}=14 \% \quad(i=1)$, $T_{f}^{0}=100$ and $T_{S, 0}=50$. It is observed that $N P V_{1,1}$ gradually decreases until year 69 , then grows again over time until $T_{S}=T_{f}^{0} . N P V_{2,1}$ follows the same trend with the same inflection point at year 69. The inflection point for $N P V_{3,1}$ is reached sooner at year 52 .

Similarly, Figures $4 \mathrm{~b}$ and $4 \mathrm{c}$ illustrate the net present value obtained with different options ( $j=1,2,3$ for welded, bolted steel plates and adhesively bonded CFRP, respectively), with $G_{S}=30 \%$ and $46 \%$, respectively. In Figure $4 \mathrm{~b}$, as corresponding cost values increase with $T_{S}$ , it is more interesting not to wait at year 50 to strengthen the bridge.

In Figure $4 \mathrm{c}$ when $G_{S}=46 \%$, it is more interesting not to wait at year 50 to strengthen the bridge and that for any of strengthening options. The net present values for each option are very 
close. Indeed, additional costs $C_{w}^{j}$ are more interesting when using CFRP. However, this advantage is neutralized when $G_{S}=46 \%$ as the unit cost per meter $c_{s, u}^{3,3}$ for CFRP is larger than those for steel plates and necessary quantities of materials are more significant than when $G_{S}=14 \%$ and $30 \%$ (see Table 4$)$.

(a)

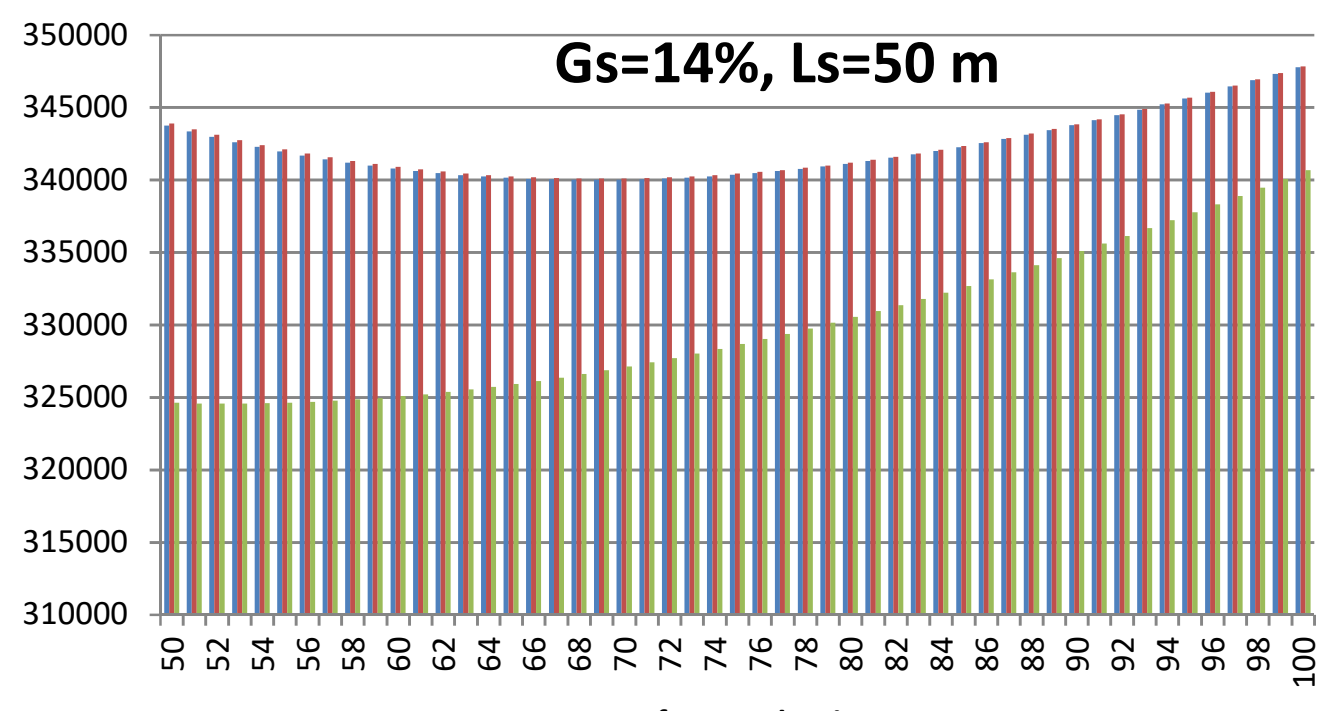

- Option 1

Option 2

Option 3

Year of strengthening $T_{s}$

(b)

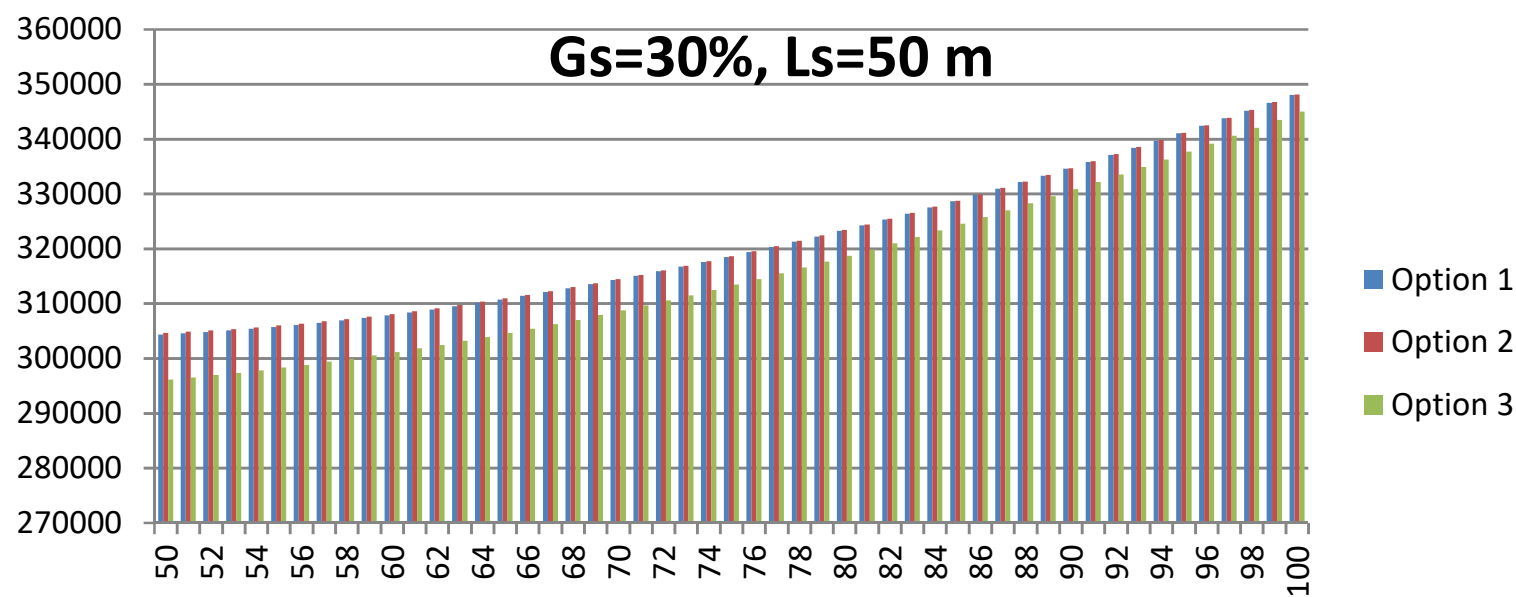

Year of strengthening $T_{s}$ 
(c)

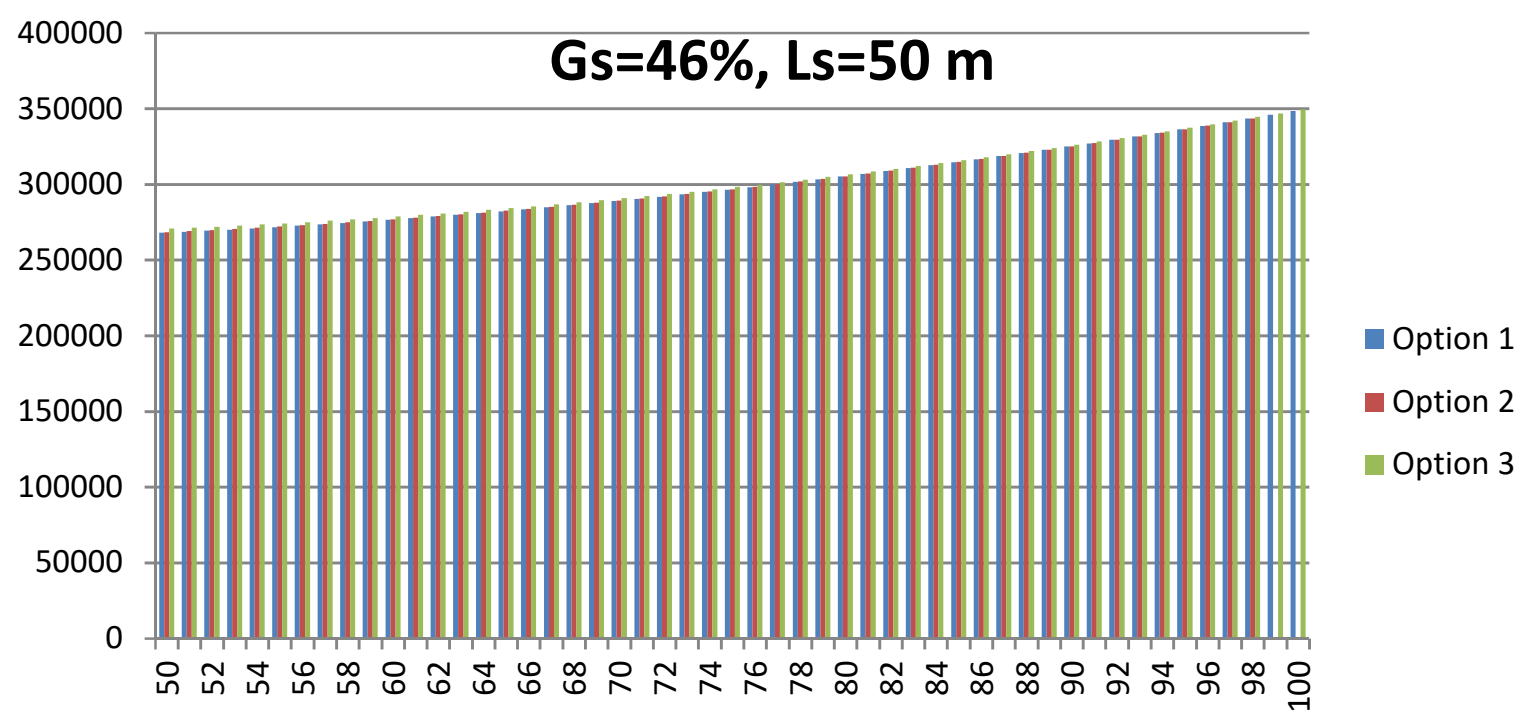

Year of strengthening $T_{s}$

Fig.4. Net present value $N P V_{j, i}$ (option $j=1,2,3$ for welded, bolted steel plates and adhesively bonded CFRP, respectively) with $L_{S}=50 \mathrm{~m}$ and (a) $G_{S}=14 \%$ ( $i=1$ ), (b)

$$
G_{S}=30 \%(i=2) \text { and (c) } G_{S}=46 \%(i=3) .
$$

One can lead an analysis based on relative differences in costs for the possible strengthening actions (including the $\mathrm{DN}$ scenario). $N P V_{j, i}$ can be compared (i) to $N P V_{0}$ to show the interest or not of preventive maintenance when compared to the DN strategy:

$$
R_{j, i}\left(T_{S}\right)=\frac{N P V_{j, i}\left(T_{S}\right)-N P V_{0}\left(T_{S}\right)}{N P V_{0}\left(T_{S}\right)}
$$

The "Do nothing" cost $\left(N P V_{0}\right)$ is fixed for any $T_{S}$ as it is always expressed in reference to year $T_{S, 0}$ and is equal to $325,000 €$ in this example. The profiles of $R_{1, i}$ (relative difference of cost for use of welded steel plates compared to the DN strategy) are given in Figures 5(a-c) when the length of strengthening area $L_{S}=50,100,150 \mathrm{~m}$, respectively. Obviously, the larger $L_{S}$ (which represents the parts of the structure needing some strengthening), the higher the reinforcement materials cost. 
(a)

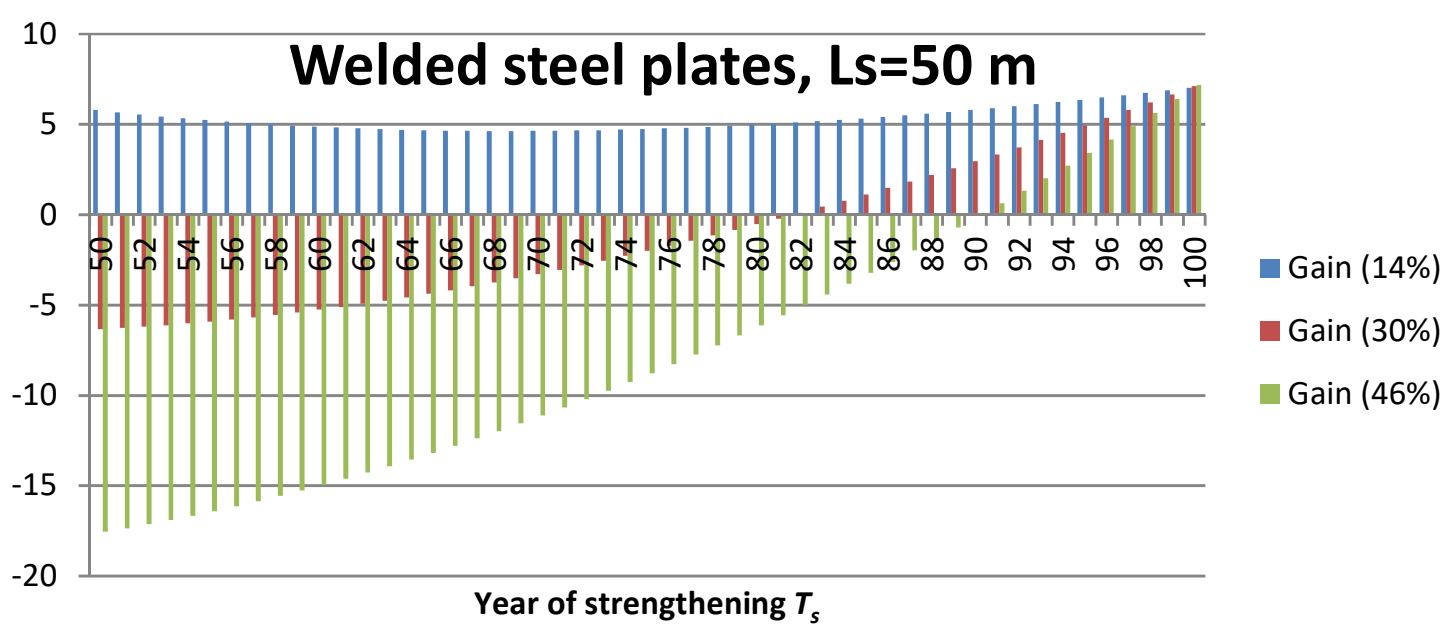

(b)

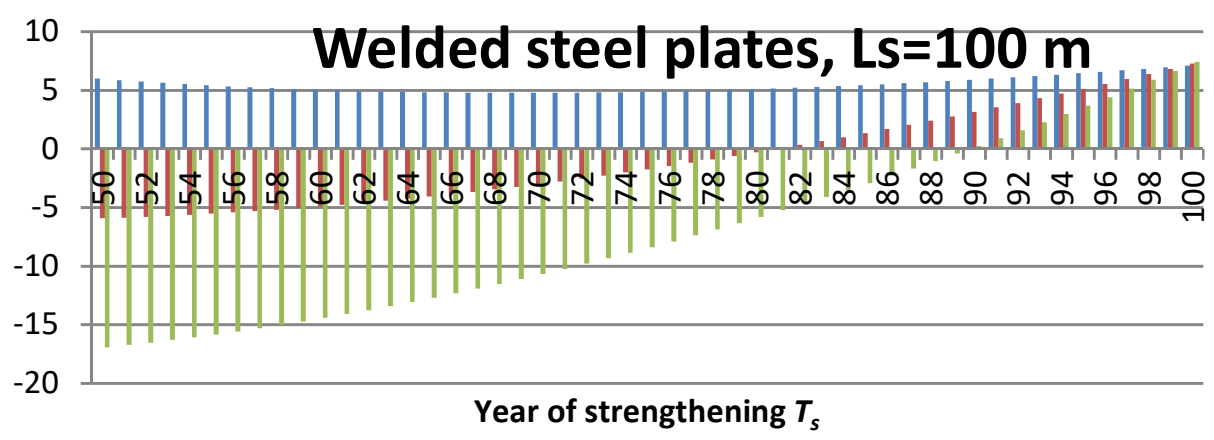

- Gain (14\%)

- Gain (30\%)

- Gain (46\%)

(c)

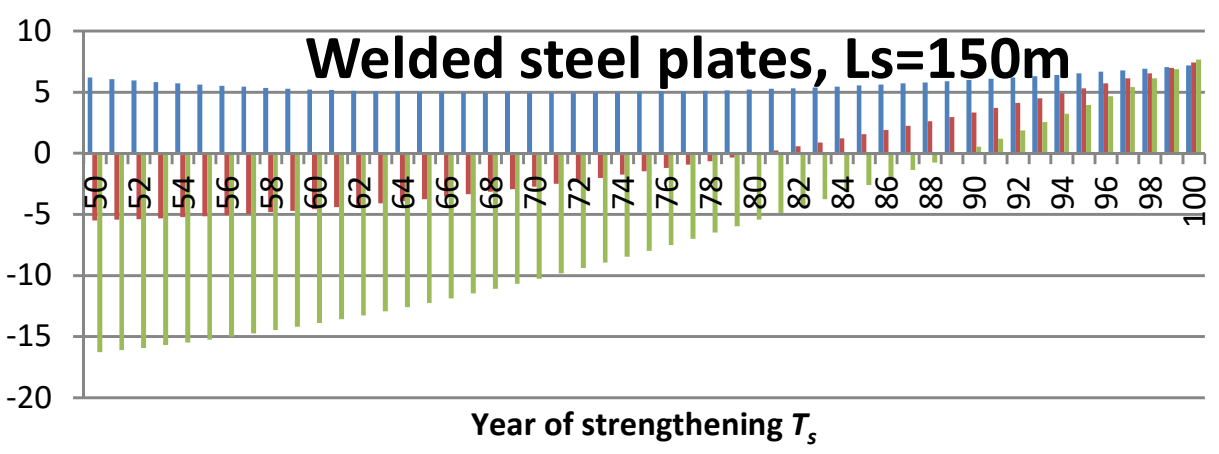

- Gain (14\%)

- Gain (30\%)

- Gain (46\%)

Fig. 5. Profiles of $R_{1, i}$ when $L_{S}=$ (a) $50 \mathrm{~m}$, (b) $100 \mathrm{~m}$, and (c) $150 \mathrm{~m}$.

It is observed that having a fatigue service life gain of $14 \%$ is never more economically attractive than doing nothing when using welded steel plates. Besides, having a gain of $30 \%$ and $46 \%$ remains more attractive than doing nothing until approximately year 80 and 90 , respectively.

The profiles of $R_{2, i}$ (relative difference of cost for use of bolted steel plates compared to the "Do nothing strategy") are given in Figures 6(a-c) when $L_{S}=50,100,150 \mathrm{~m}$, respectively. With a fatigue service life gain of $14 \%$, it is never more economically attractive than doing 
nothing when using bolted steel plates. As for welded steel plates, having a gain of $30 \%$ and $46 \%$ remains more attractive than doing nothing until approximately year 80 and 90, respectively. Similar results between welded and bolted steel plates is not surprising as cost of maintenance works are close for these two techniques.

(a)

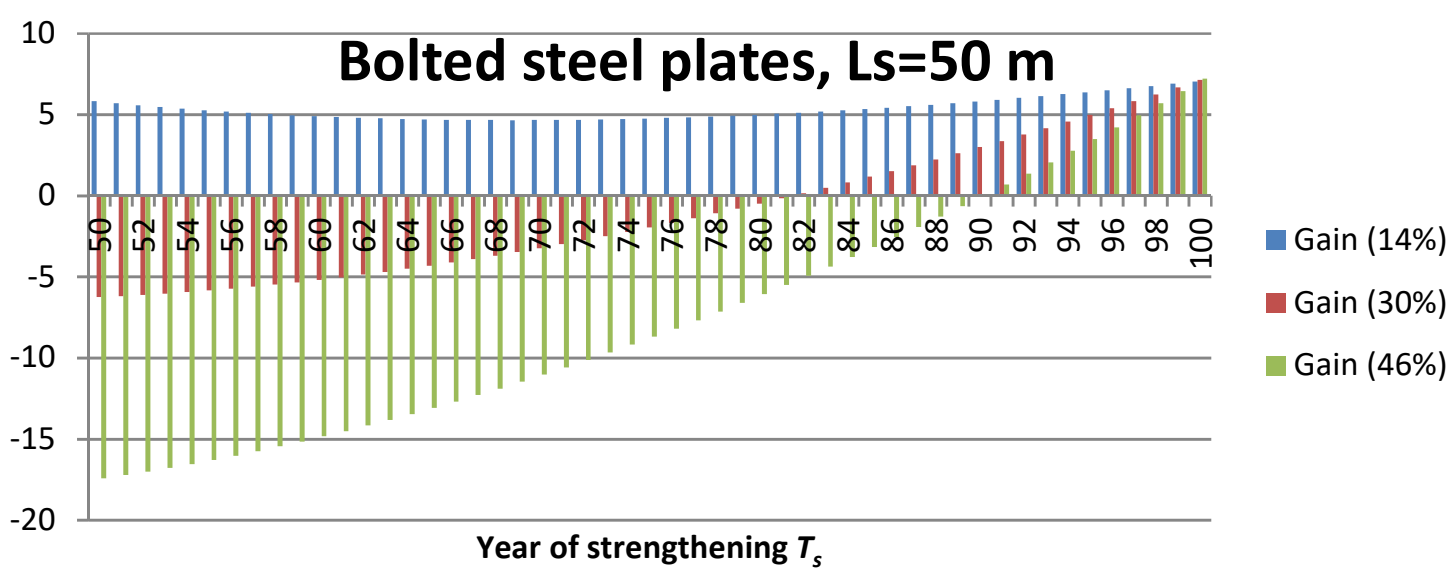

(b)

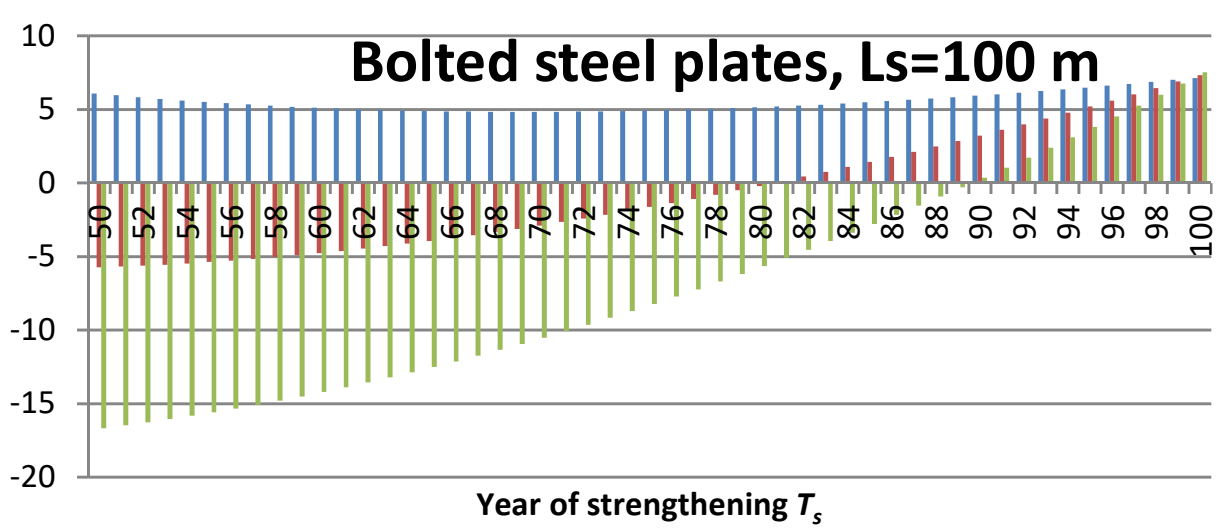

- Gain (14\%)

- Gain (30\%)

- Gain (46\%)

(c)

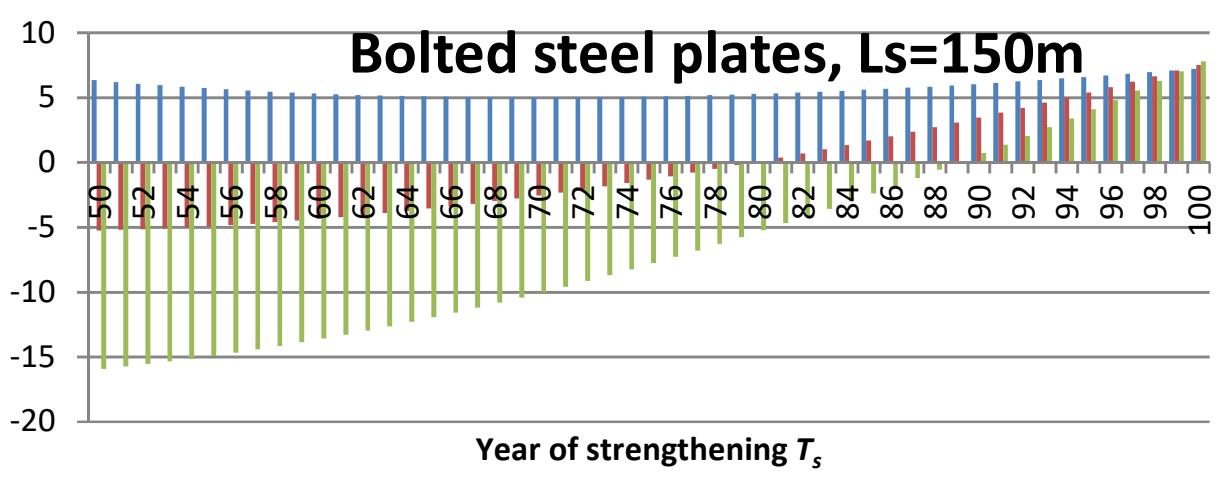

Gain (14\%)

- Gain (30\%)

Gain (46\%)

Fig. 6. Profiles of $R_{2, i}$ when $L_{S}=$ (a) $50 \mathrm{~m}$, (b) $100 \mathrm{~m}$, and (c) $150 \mathrm{~m}$.

The profiles of $R_{3, i}$ (relative difference of cost for use of CFRP compared to the "Do nothing strategy") are given in Figures $7(\mathrm{a}-\mathrm{c})$ when $L_{S}=50,100,150 \mathrm{~m}$, respectively. Contrary to 
welded and bolted steel plates solutions, CFRP technique can be more interesting than doing nothing when $L_{S}=50 \mathrm{~m}$, until years 60,85 and 89 , respectively, when $G_{S}=14 \%, 30 \%$, and $46 \%$, due to the saving in additional costs $\left(C_{w}^{3}\right.$ lower than $C_{w}^{1}$ or $\left.C_{w}^{2}\right)$. When $L_{S}=100 \mathrm{~m}, \mathrm{CFRP}$ shows some benefits until years 71 and 80 , respectively, when $G_{S}=14 \%$ and $30 \%$. Finally, the use of CFRP is never more financially attractive than doing nothing when $L_{S}=150 \mathrm{~m}$, due to the high unit costs of materials.

(a)

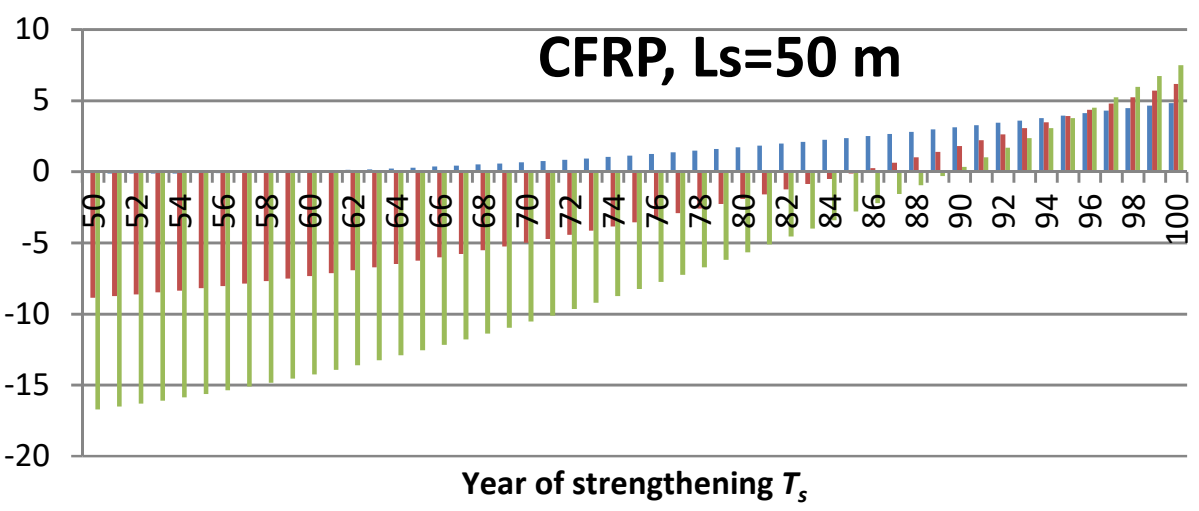

- Gain (14\%)

- Gain (30\%)

$\square$ Gain (46\%)

(b)

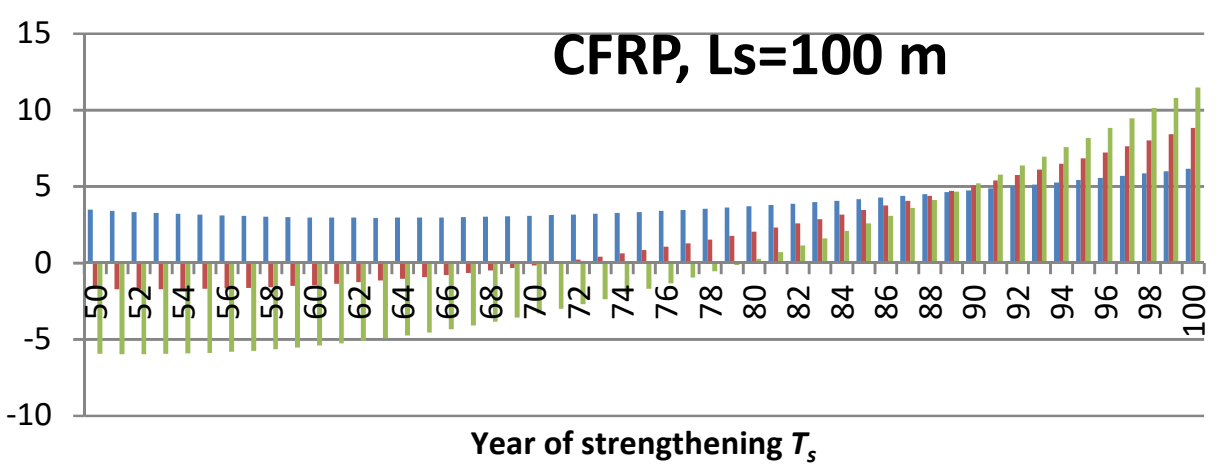

Gain (14\%)

- Gain (30\%)

Gain (46\%)

(c)

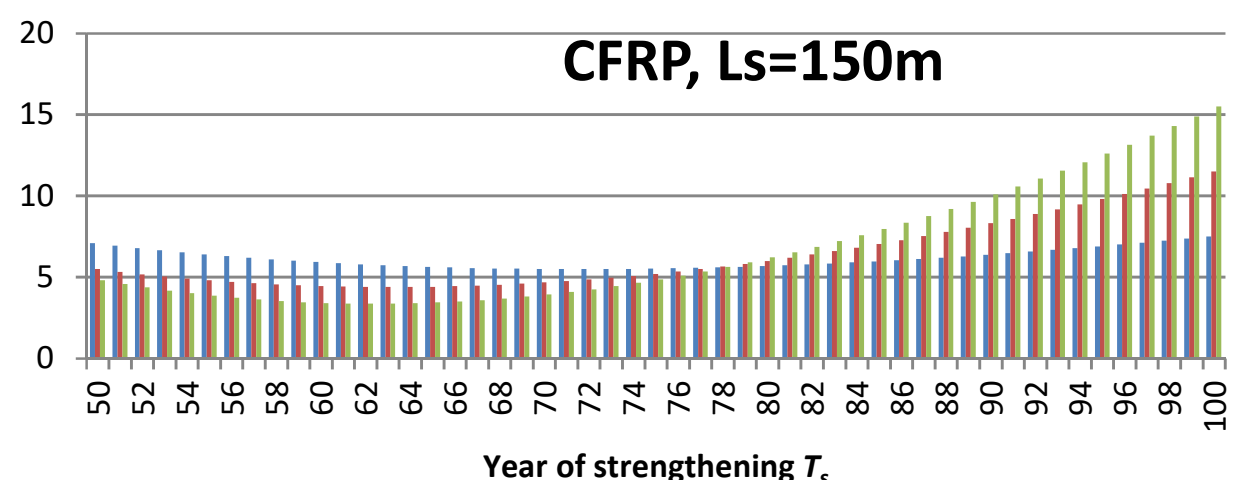

Gain (14\%)

Gain (30\%)

Gain (46\%)

Fig. 7. Profiles of $R_{3, i}$ when $L_{S}=$ (a) $50 \mathrm{~m}$, (b) $100 \mathrm{~m}$, and (c) $150 \mathrm{~m}$. 


\subsection{SENSITIVITY ANALYSIS}

One investigates the impact of two key parameters on the decision making process, namely:

- the yearly discount rate of money $r$,

- the end-of-life costs including decommissioning and reconstruction.

As net present value costs are similar for welded and bolted steel plates options, results are only shown for welded $(j=1)$ and CFRP $(j=3)$ techniques.

\subsubsection{IMPACT OF THE YEARLY DISCOUNT RATE OF MONEY}

In this section, all the input parameters are those of Table 5 except the values of $r$. The profiles of $R_{1, i}$ (relative difference of cost for use of welded steel plates compared to the "Do nothing strategy") are given in Figures 8(a-c) when $L_{S}=50 \mathrm{~m}$, with $r=2 \%, 4 \%$ and $6 \%$, respectively. Unsurprisingly, the yearly discount rate of money can significantly change results of the analysis and impact the opinion of the decision maker when comparing strengthening actions to a "Do nothing" strategy. In particular, a high discount rate decreases the weight of the end of life costs and increases the weight of the direct strengthening costs. In other words, the higher the discount rate, the lower the present value of the future costs and in the same way the lower the initial costs should be. Such aspects, related to Equation 4, explain the change of the profile for $R_{1, i}$ that tends to increase and even be positive in the short term period after year 50 (compare Figures $8 \mathrm{a}, 8 \mathrm{~b}$, and $8 \mathrm{c}$ ) with the optimal time for strengthening that shifts to the right of the time profile.

(a)

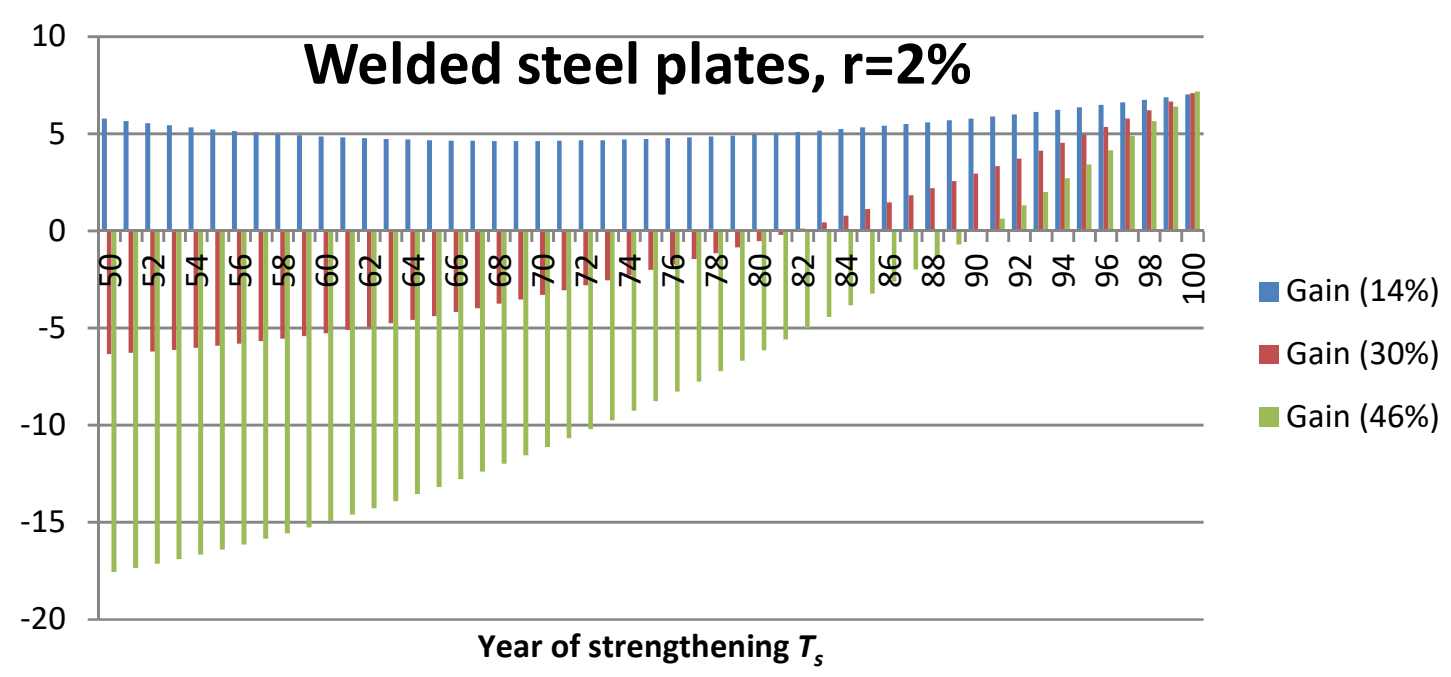




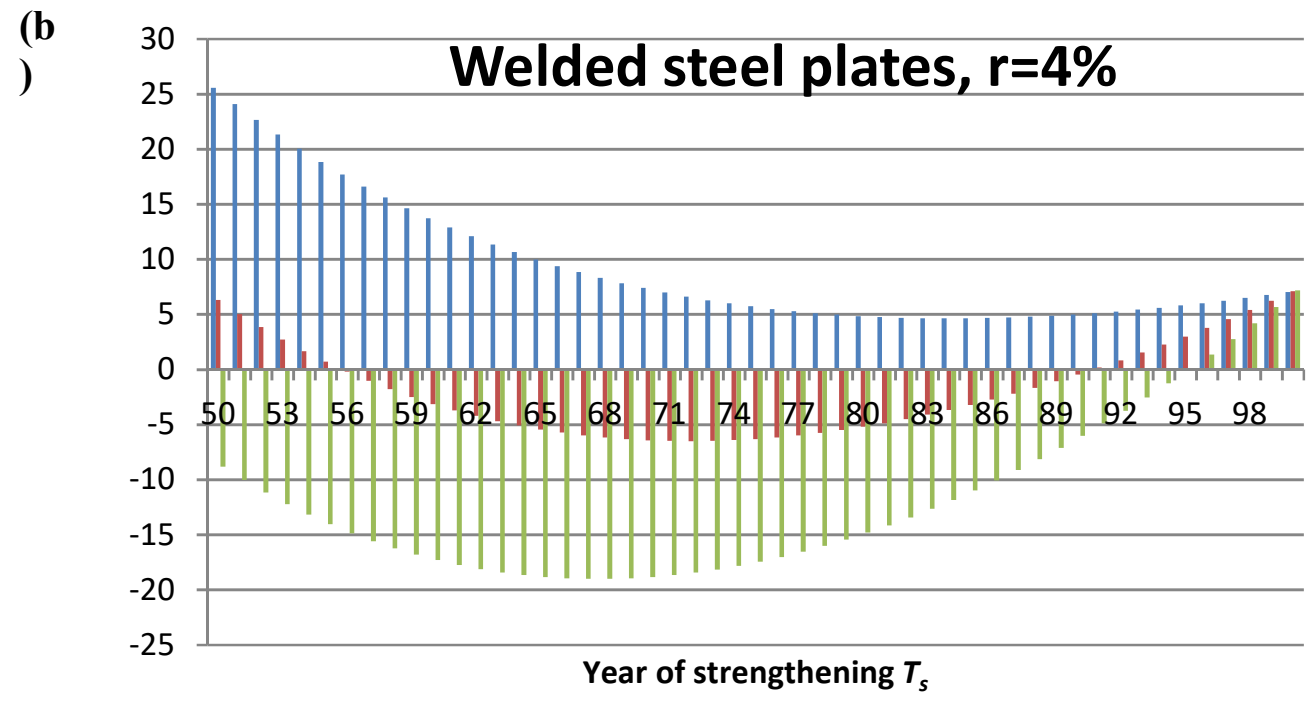

- Gain (14\%)
- Gain (30\%)
Gain (46\%)

(c)

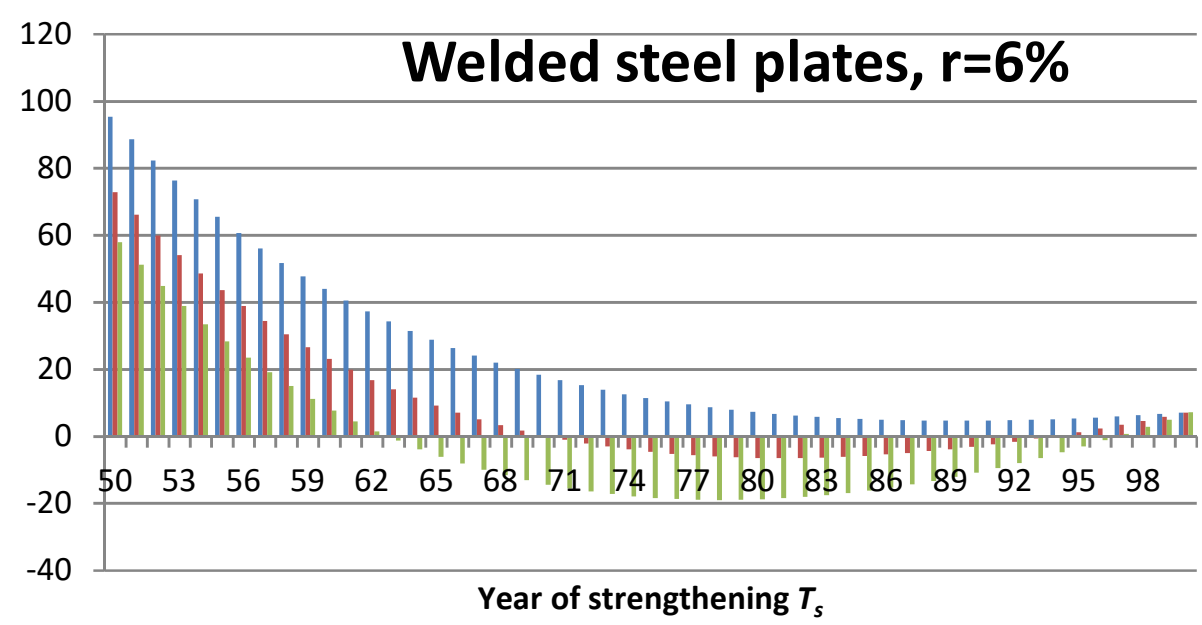

Fig. 8. Profiles of $R_{1, i}$ when $L_{S}=50 \mathrm{~m}$ with (a) $r=2 \%$, (b) $r=4 \%$, and (c) $r=6 \%$.

The profiles of $R_{3, i}$ (relative difference of cost for use of CFRP compared to the "Do nothing strategy") are given in Figures 9(a-c) when $L_{S}=50 \mathrm{~m}$, with $r=2 \%, 4 \%$ and $6 \%$, respectively. The cost of works are different for options 1 and 3, and then the comparison differs from Figure 8 to Figure 9 (although the curvature of profiles change in a similar way in both figures). In particular, the increase in discount rate is favorable to the adhesively bonded CFRP since it lowers the weight of direct costs (larger for adhesively bonded CFRP than for welded steel) when compared to a Do Nothing option. 
(a)

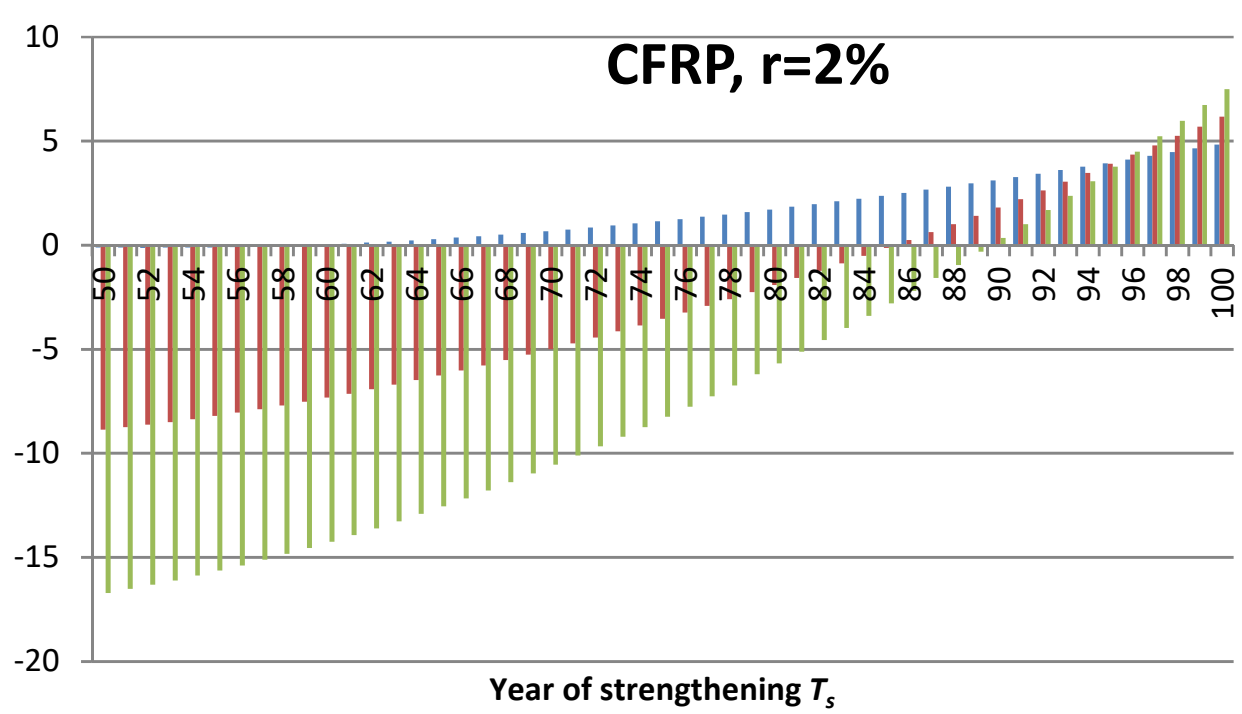

- Gain (14\%)

- Gain $(30 \%)$

- Gain $(46 \%)$

(b)

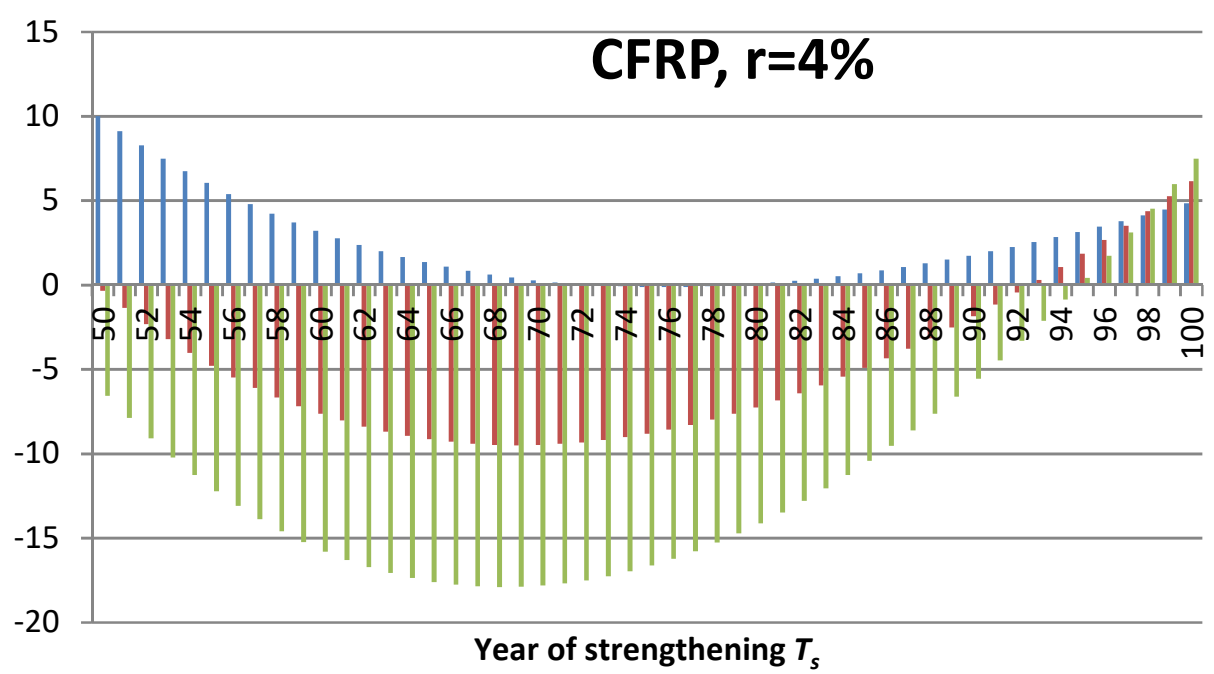

Gain (14\%)

Gain (30\%)

Gain (46\%)

(c)

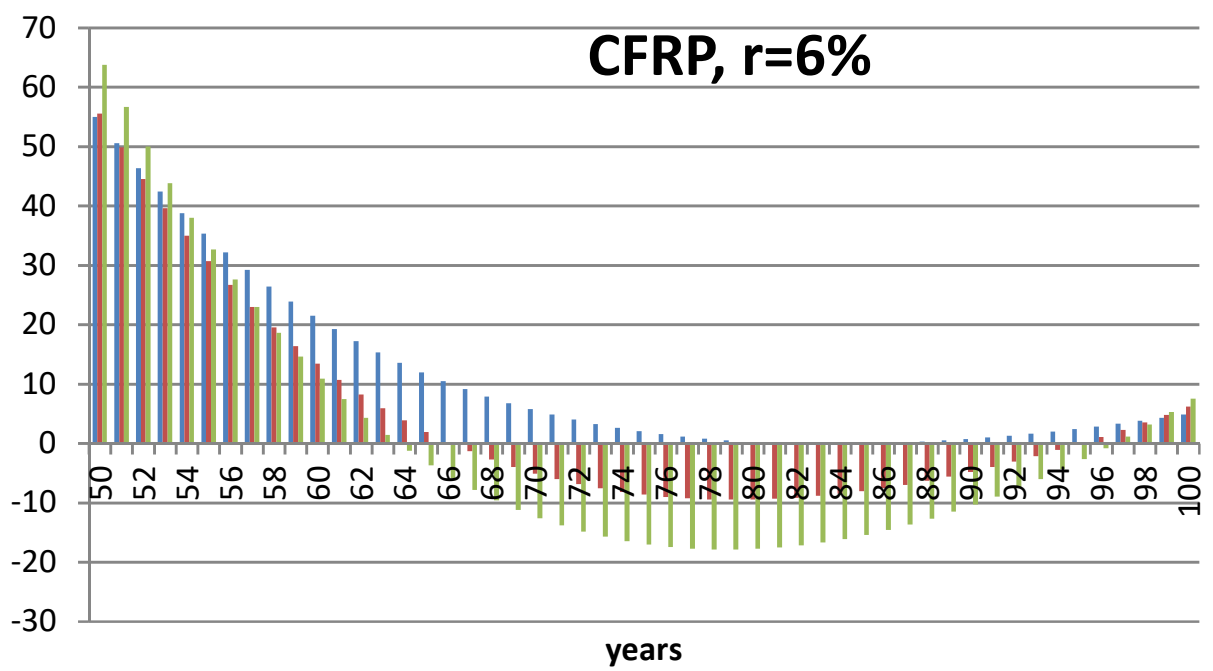

Fig. 9. Profiles of $R_{3, i}$ when $L_{S}=50 \mathrm{~m}$ with (a) $r=2 \%$, (b) $r=4 \%$, and (c) $r=6 \%$. 


\subsubsection{IMPACT OF THE END-OF-LIFE COSTS}

All the input parameters are those of Table 5 except the values of $C_{f}$. The profiles of $R_{1, i}$ (relative difference of cost for use of welded steel plates compared to the "Do nothing strategy") are given in Figures $10(\mathrm{a}-\mathrm{c})$ when $L_{s}=50 \mathrm{~m}$, with $C_{f}=800 € / \mathrm{m}^{2}, C_{f}=900 € / \mathrm{m}^{2}$ and $C_{f}=1000 € / m^{2}$ respectively. In this example, the variation of $C_{f}$ does not dramatically impact the profiles of discounted costs, though it changes the optimal year of maintenance to maximize the financial benefit.

(a)

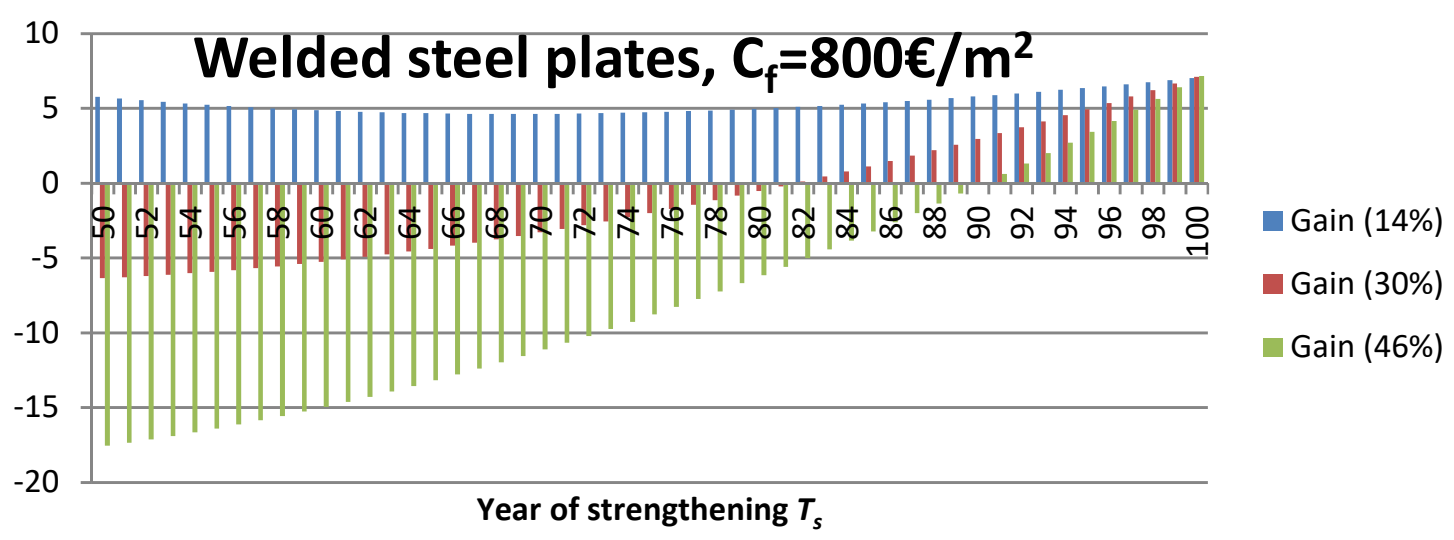

(b)

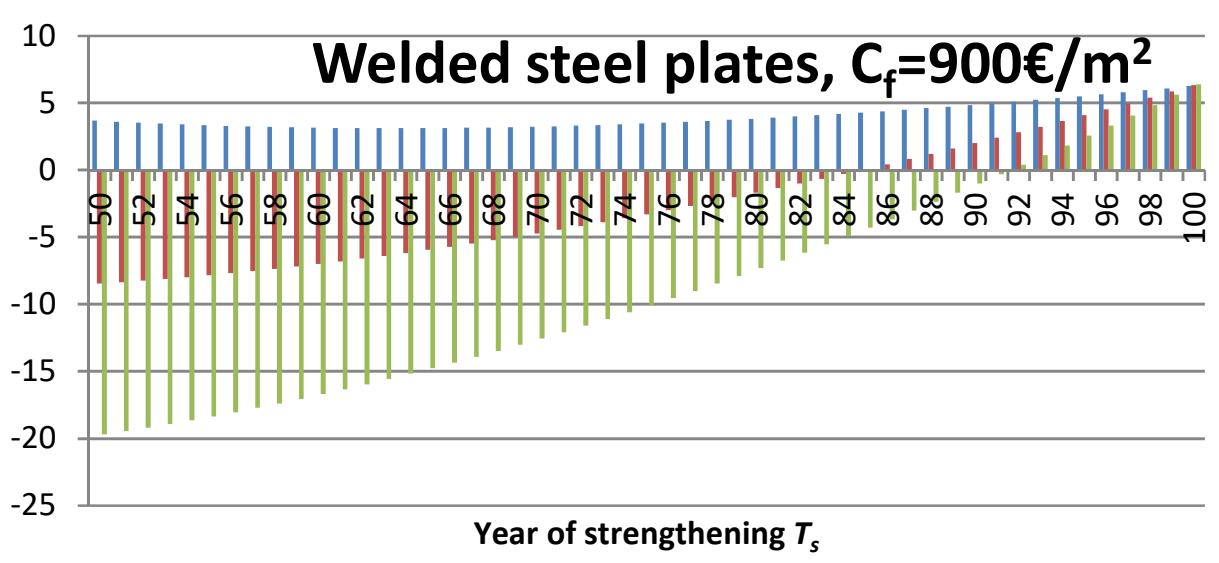

- Gain (14\%)

- Gain (30\%)

Gain (46\%) 
(c)

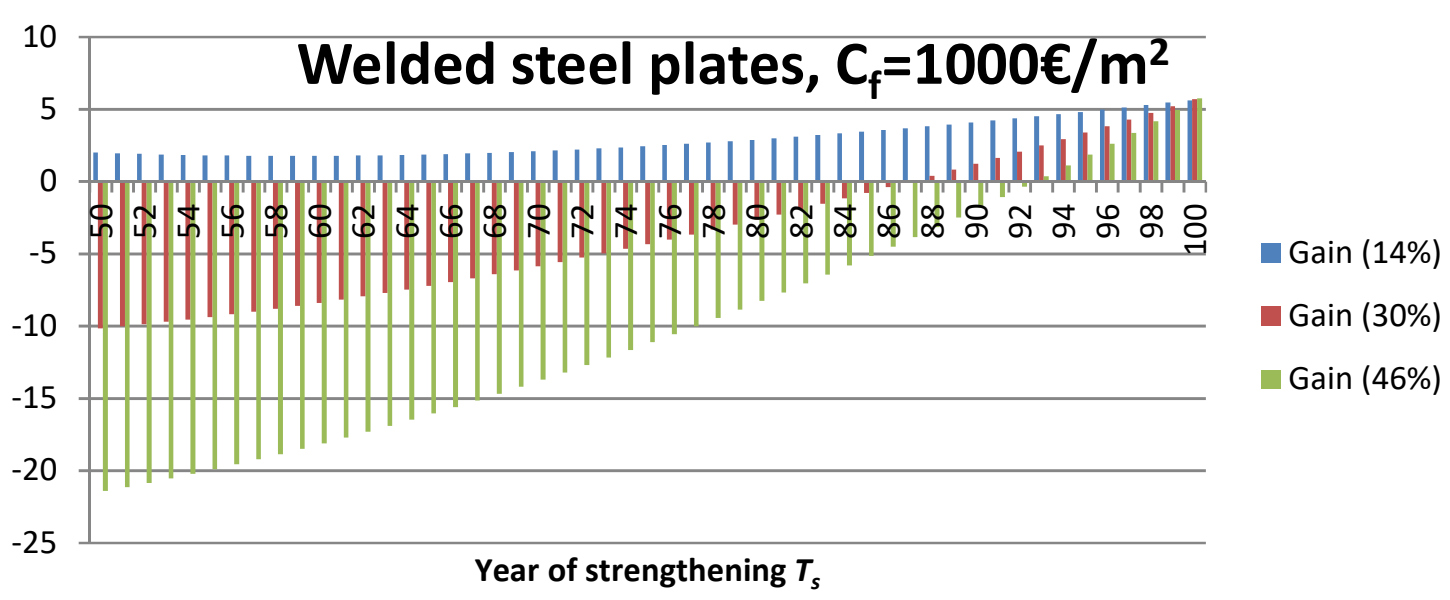

Fig. 10. Profiles of $R_{1, i}$ when $L_{s}=50 \mathrm{~m}$ with (a) $C_{f}=800 € / \mathrm{m}^{2}$, (b) $C_{f}=900 € / \mathrm{m}^{2}$, and (c) $C_{f}=1000 € / m^{2}$.

Similarly, the profiles of $R_{3, i}$ (relative difference of cost for use of CFRP compared to the "Do nothing strategy") are given in Figures $11(\mathrm{a}-\mathrm{c})$ when $L_{S}=50 \mathrm{~m}$, with $C_{f}=800 € / \mathrm{m}^{2}$, $C_{f}=900 € / \mathrm{m}^{2}$ and $C_{f}=1000 € / \mathrm{m}^{2}$ respectively. Same conclusions can be drawn with the use of CFRP. The end-of-life costs can impact the optimal year of maintenance although the net present value profiles are not significantly changed. In particular, the higher the end-of-life costs, the more beneficial the strengthening action when considered as soon as possible.

(a)

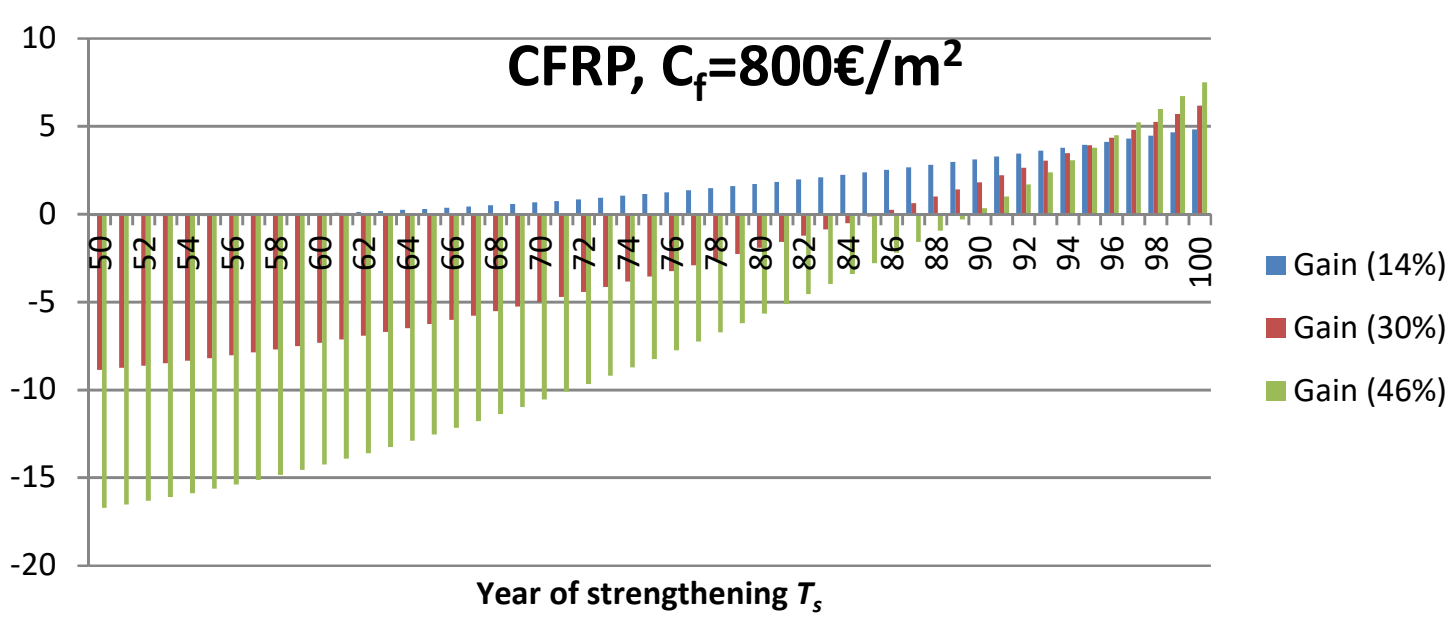


(b)

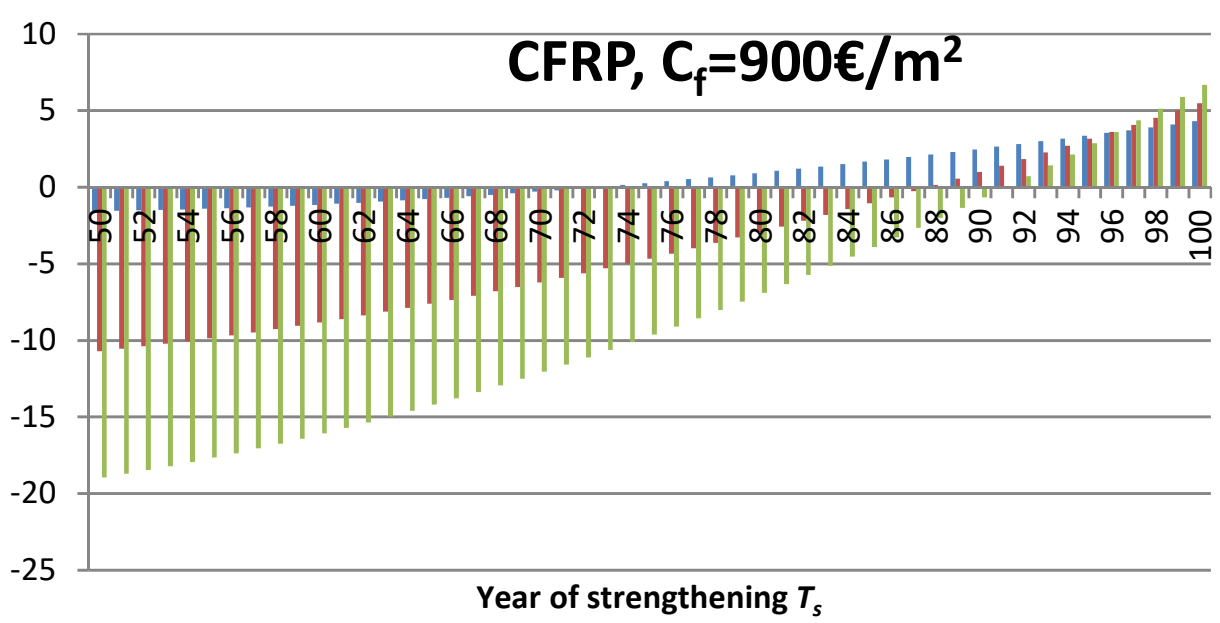

Gain (14\%)

Gain (30\%)

Gain (46\%)

(c)

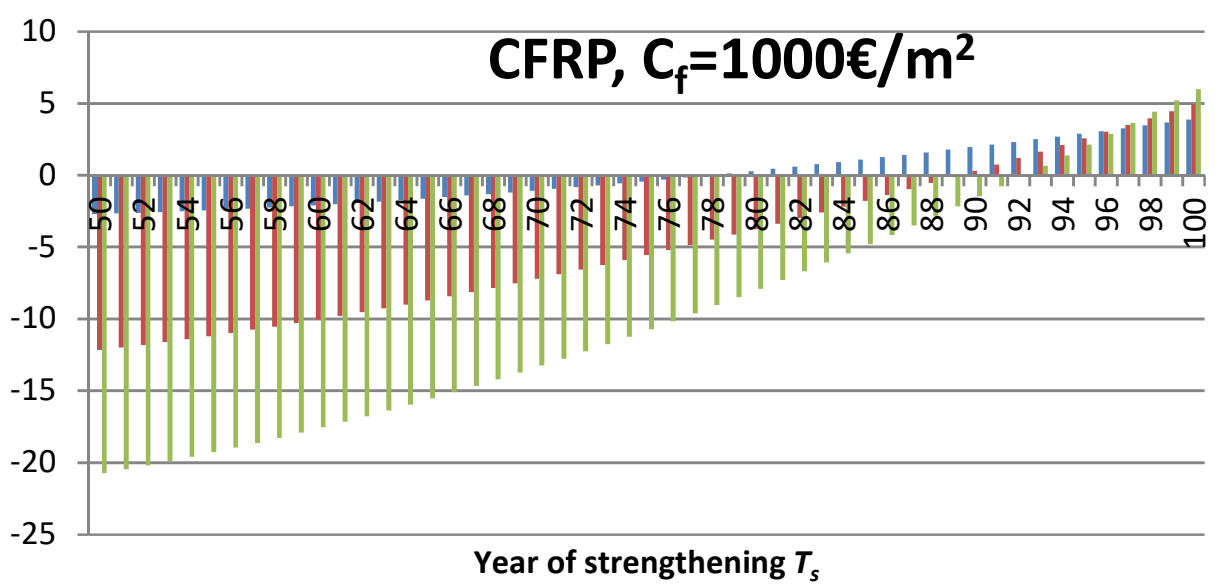

Gain (14\%)

Gain (30\%)

Gain (46\%)

Fig. 11. Profiles of $R_{3, i}$ when $L_{S}=50 \mathrm{~m}$ with (a) $C_{f}=800 € / \mathrm{m}^{2}$, (b) $C_{f}=900 € / \mathrm{m}^{2}$, and

(c) $C_{f}=1000 € / m^{2}$.

\section{USER COSTS ASSESSMENT}

Social analysis should be considered along with other aspects when making decisions during the overall service life. In particular, user costs enable to quantify, in economic terms, the potential safety and mobility benefits of functional improvements to bridges. One proposes herein a framework to calculate additional user costs in case of maintenance works. Such user costs may represent a significant portion of costs at stake and need to be considered in the overall decision making process. In this paper, the social analysis is carried out using the model QUEWZ-98 [25] [26] [27].

The user costs include traffic delay, vehicle operating and accident costs detailed below: 
- traffic delay costs are influenced by many factors such as current and future traffic, bridge capacity, the timing, duration, and frequency of work-zone-induced capacity restrictions, and the unit costs for delay;

- vehicle operating costs are due to the level of service loss caused by the maintenance operations on highway structures. The disruption of normal traffic causes speed reductions, increase of fuel and oil consumptions, tire wear and vehicle maintenance. In particular, additional cost of fuel is due to the fact that its consumption is significantly higher in congested conditions. Besides, vehicle maintenance costs increase since these items need faster replacement for vehicles travelling in congested conditions;

- accident costs are due to the increase of accident risks, healthcare and deaths related to the change of traffic condition.

\subsection{DRIVER'S DELAY COSTS}

It is possible to calculate the DDC (driver's delay cost)[26][27] [28] as follows:

$$
D D C=\left(\frac{L}{V_{t}}-\frac{L}{V_{n}}\right) \times N \times A D T \times \sum_{i=1}^{2}\left(D T C_{i} \times p_{i}\right)
$$

with $L$ the length of the road work area. $V_{t}$ the restricted speed in the work area, $V_{n}$ the speed without work, $N$ the number of work days, $A D T$ the average daily traffic, $D T C_{i}$ the cost per hours for a driver of a vehicle class $i$ and $p_{i}$ the percentage of vehicle class $i$.

The traffic modeling is divided in five sections: the deceleration at the approach of the work area, the bottled zone, the first acceleration zone, the area of work and finally the second acceleration zone. With such a discretization (both for different traffic area and daily traffic distribution), Equation 6 becomes:

$$
D D C=\sum_{j=1}^{24}\left[\sum_{k=1}^{5}\left(\frac{L_{k}}{V_{t_{k}}}-\frac{L_{k}}{V_{n}}\right) \times H T \times \sum_{i=1}^{2}\left(D T C_{i} \times p_{i}\right)\right] \times N
$$

with $L_{k}$ the length traffic section $k, V_{t_{k}}$ the speed in section $k, V_{n}$ the speed without work, $H T$ the hourly traffic, $D T C_{i}$ the cost per hours for a driver of a vehicle class $i, p_{i}$ the percentage of vehicle class $i$ and $N$ the number of work days.

\subsection{VEHICLE OPERATING COSTS}

The VOC (Vehicle Operating Costs) is calculated as [26][27] [28]: 


$$
V O C=\left(L-\frac{V_{t}}{V_{n}} \times L\right) \times N \times A D T \times \sum_{i=1}^{2}\left(V O C_{i} \times p_{i}\right)
$$

With $L$ the length of the work $V_{t}$ the speed in the work zone, $V_{n}$ the speed without work, $N$ the number of work days, $A D T$ average daily traffic, $V O C_{i}$ operating costs of vehicle of class $i$ and $p_{i}$ the percentage of vehicle class $i$.

As for the calculation of DDC, the work zone is separated in five sections. The expression of VOC is then :

$$
V O C=\sum_{j=1}^{24}\left[\sum_{k=1}^{5}\left(L_{k}-\frac{V_{t k}}{V_{n}} \times L_{k}\right) \times H T \times \sum_{i=1}^{2}\left(V O C_{i} \times p_{i}\right)\right] \times N
$$

\subsection{ACCIDENTS COSTS}

The risk of accident is increasing with the congestion of traffic. There is consequently additional costs for the accident in the work zone which can be expressed as [28] [29] [30]:

$$
A C=L \times A D T \times N \times\left(T_{t}-T_{n}\right) \times P_{a}
$$

with $T_{t}$ the accident rate during work, $T_{n}$ the accident rate without work and $P_{a}$ the cost of accident.

As for $D D C$ and $V O C$, the work zone is separated in five sections. Three categories of accidents are introduced: light, moderate and severe and included in a general expression of accident costs:

$$
A C=L \times A D T \times N \times\left\{\sum_{j=1}^{3}\left[\left(T A a_{j}-T A n_{j}\right) \times p a_{j}\right]+\sum_{k=1}^{3}\left[\left(T V a_{k}-T V n_{k}\right) \times p v_{k}\right]\right\}
$$

With $T A a_{j}$ the rate of class $j$ accident during work, $T A n_{j}$ the rate of class $j$ accident without work, $p a_{j}$ the price of the assistance of class $j$ accident, $T V a_{k}$ the rate of class $k$ victim during work, $T V n_{k}$ the rate of class $k$ victim without work, $p v_{k}$ the price of the intervention for a class $k$ victim.

\subsection{ILLUSTRATION OF USER COSTS}

The example considered in section 3 for illustration of direct cost assessment is used herein to perform the societal analysis, based on the concepts presented in sections 4.1, 4.2 and 4.3. During the time period when traffic restrictions are applied, it is assumed that the traffic remains 
the same and that only the bridge capacity is reduced. The traffic considered is detailed in number of vehicles passing over the bridge per hour.

The input parameters used in the calculation of user costs are detailed in Table 6.

Table 6. Parameters considered in the user cost analysis.

\begin{tabular}{ll}
\hline Description & Value \\
Hour of restricted capacity - beginning (min->0) & $9 \mathrm{~h}$ \\
Hour of restricted capacity - ending (max->24) & $15 \mathrm{~h}$ \\
Hour of work zone activity - beginning & $9 \mathrm{~h}$ \\
Hour of work zone activity - ending & $15 \mathrm{~h}$ \\
SP1 (Normal) & $96 \mathrm{~km} / \mathrm{h}$ \\
SP2 (restricted) & $74 \mathrm{~km} / \mathrm{h}$ \\
SP3 (working hours) & $48 \mathrm{~km} / \mathrm{h}$ \\
Capacity V1 (normal) & $6,600 \mathrm{vphp} 1^{*}$ \\
Capacity V2 (restricted) & $1,980 \mathrm{vphpl}$ \\
Capacity V3 (working hours) & $1,570 \mathrm{vphpl}$ \\
Length of work zone & $1.6 \mathrm{~km}$ \\
Percentage of trucks & $10 \%$ \\
Cost/car/hour in $€$ & $11.25 €$ \\
Cost/car/Km in $€$ & $0.25 €$ \\
Cost/truck/hour in $€$ & $20.55 €$ \\
Cost/truck/Km in $€$ & $0.45 €$
\end{tabular}

*vphpl: vehicles per hour per lane

It is assumed that there is no traffic considered underneath the bridge. Three traffic configurations are tested to assess the sensitivity of the model:

- Configuration Ta 1 : with parameters as indicated in Table 6,

- Configuration Ta2: configuration Ta 1 with capacities V2 and V3 fixed at 3300 vphpl during restricted hours (to analyze the effect of traffic capacity),

- Configuration $\mathrm{Ta}_{3}$ : configuration Ta $\mathrm{T}_{1}$ with hourly traffic volume increased by $20 \%$ (to analyze the effect of traffic distribution).

Figure 12 illustrates the daily traffic configuration and capacity (with and without works) for these three configurations. The overall additional user costs (sum of costs for cars and trucks) for one day and for the assumed durations for each strengthening solution (12 days of works 
for welded and bolted steel plates and 5 days of works for adhesively bonded CFRP) are detailed in Table 7.

(a)

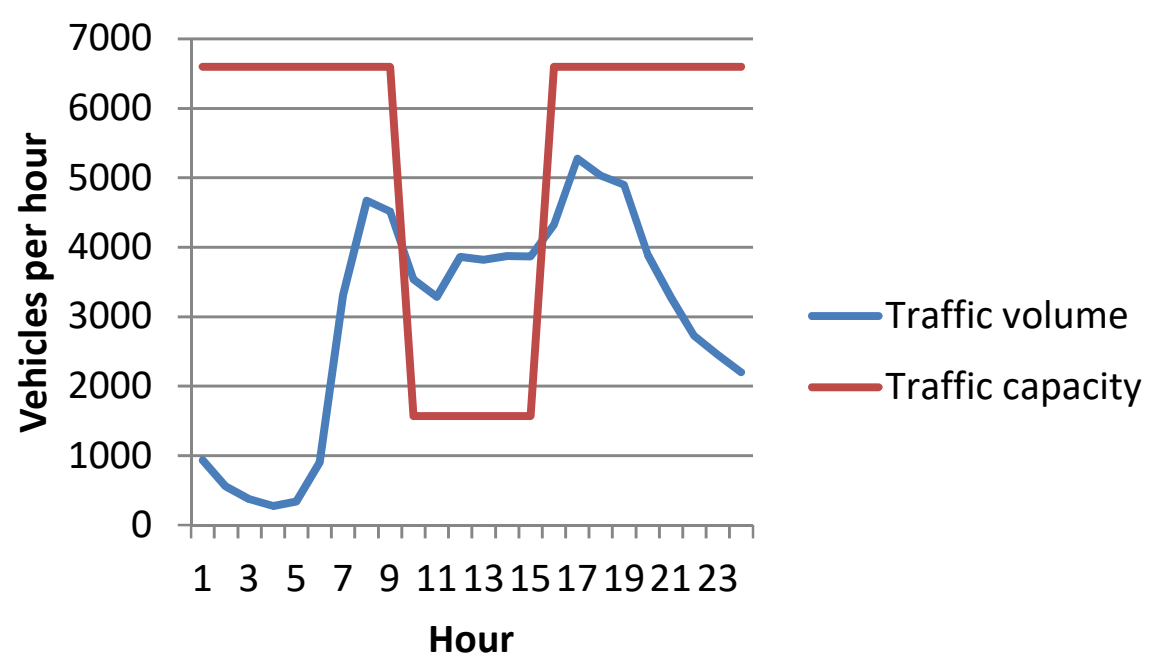

(b)

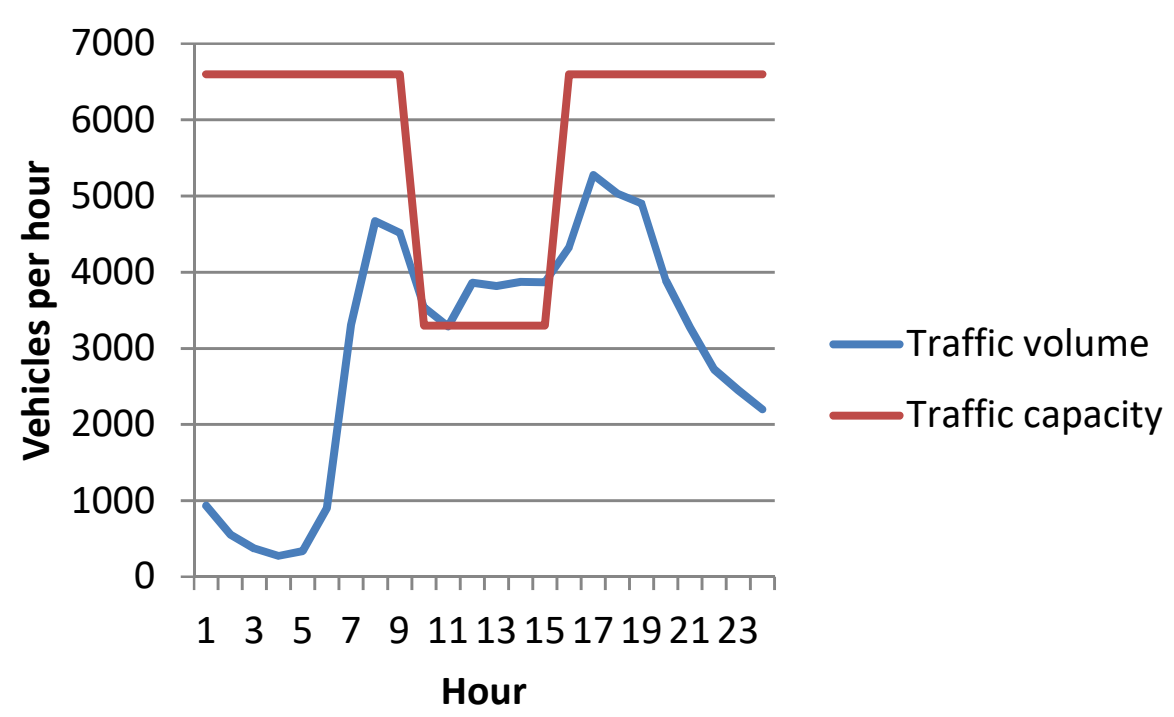


(c)

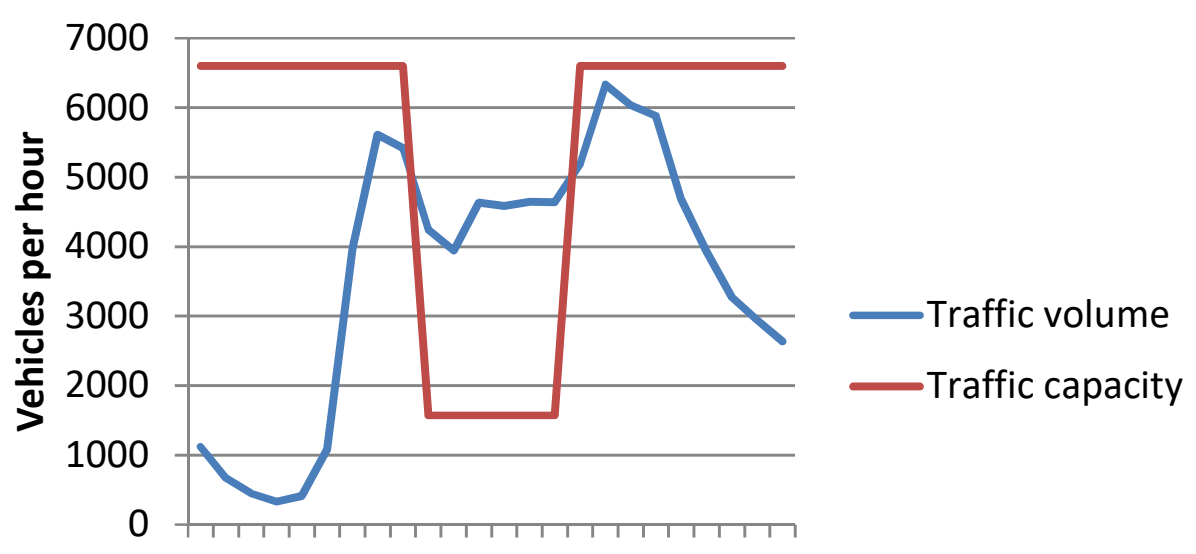

$1 \quad 3 \quad 5 \quad 7 \quad 911131517192123$

Hour

Fig. 12. Daily traffic configuration and capacity for traffic configurations (a) $\mathrm{Ta}_{1}$, (b) $\mathrm{Ta}_{2}$ and (c) $\mathrm{Ta}_{3}$.

Table 7. User cost details in traffic configurations $\mathrm{Ta}_{1}, \mathrm{Ta}_{2}$ and $\mathrm{Ta}_{3}$.

\begin{tabular}{|c|c|c|c|c|}
\hline $\begin{array}{c}\text { Strengthening } \\
\text { solution }\end{array}$ & $\begin{array}{r}\text { Daily } \\
(\epsilon)\end{array}$ & cost & $\begin{array}{c}\text { Number of work } \\
\text { days }\end{array}$ & $\begin{array}{l}\text { Total user costs during work } \\
\text { period }(€)\end{array}$ \\
\hline \multicolumn{5}{|c|}{ Configuration Ta1 } \\
\hline Welded steel plates & & & 12 & 278,400 \\
\hline \multicolumn{2}{|l|}{ Bolted steel plates } & & 12 & 278,300 \\
\hline \multicolumn{3}{|c|}{$\begin{array}{l}\text { Adhesively bonded } 23,200 \\
\text { CFRP }\end{array}$} & 5 & 116,000 \\
\hline \multicolumn{5}{|c|}{ Configuration Ta2 } \\
\hline \multirow{2}{*}{\multicolumn{2}{|c|}{ Welded steel plates }} & & 12 & 192,000 \\
\hline \multirow{2}{*}{\multicolumn{3}{|c|}{$\begin{array}{l}\text { Bolted steel plates } \\
\text { Adhesively bonded } 16,000 \\
\quad \text { CFRP }\end{array}$}} & 12 & 192,000 \\
\hline & & & 5 & 80,000 \\
\hline \multicolumn{5}{|c|}{ Configuration $\mathrm{Ta}_{3}$} \\
\hline \multirow{2}{*}{\multicolumn{3}{|c|}{$\begin{array}{l}\text { Welded steel plates } \\
\text { Bolted steel plates }\end{array}$}} & 12 & 398,400 \\
\hline \multirow{2}{*}{\multicolumn{3}{|c|}{$\begin{array}{l}\text { Bolted steel plates } \\
\text { Adhesively bonded } 33,188 \\
\text { CFRP }\end{array}$}} & 12 & 398,400 \\
\hline & & & 5 & 166,000 \\
\hline
\end{tabular}

The three traffic configurations considered herein show that user costs strongly depend on the traffic flow, the traffic capacity during restriction and the number of days of restricted traffic. In some cases, user costs are in the same order of magnitude than direct costs, which shows the importance of this external cost in the decision making process. 


\section{ENVIRONMENTAL ANALYSIS}

LCA methodology aims evaluating the product on its entire life cycle, from cradle to grave, through different impact indicators, as detailed in Table 8 (climate change, eutrophication...). The multicriteria aspect of LCA allows avoiding a pollution transfer from one environment to another. Adaptation of LCA method in the construction field can be really complex as mentioned in the review conducted by [31]. In this paper, LCA method has been undertaken complying with the standards 14040 at 14044 of the International Organization for Standardization (1SO) [32] [33]. The indicators in Table 8 are assessed according to the European standard NF EN 15804 [34]. It is highlighted that the methods shown in Table 8 have been chosen for their international representativeness.

Table 8. Environmental impact indicators considered in the life-cycle analysis and calculation methods used (CML, EDIP and CED).

\begin{tabular}{|c|c|c|}
\hline Environmental indicator & Unit & Calculation method used \\
\hline $\begin{array}{l}\text { Consumption of energy } \\
\text { resources } \\
\text { Renewable energy } \\
\text { Non renewable energy }\end{array}$ & MJ & Cumulative Energy Demand (CED) \\
\hline $\begin{array}{l}\text { Depletion of abiotic } \\
\text { resources }\end{array}$ & $\begin{array}{l}\mathrm{kg} \quad \mathrm{eq} \\
\text { antimony }\end{array}$ & $\begin{array}{l}\text { Impact-oriented characterisation (CML } \\
\text { 2001) }\end{array}$ \\
\hline Wastes & $\mathrm{kg}$ & $\begin{array}{l}\text { Environmental Design of Industrial Products } \\
\text { (EDIP) }\end{array}$ \\
\hline Radioactive wastes & $\mathrm{kg}$ & $\begin{array}{l}\text { Environmental Design of Industrial Products } \\
\text { (EDIP) }\end{array}$ \\
\hline Climate change & $\mathrm{Kg}$ eq $\mathrm{CO}_{2}$ & $\begin{array}{l}\text { Impact-oriented characterisation } \\
\text { 2001) }\end{array}$ \\
\hline Acidification potential & $\mathrm{Kg}$ eq $\mathrm{SO}_{2}$ & $\begin{array}{l}\text { Impact-oriented characterisation } \\
\text { 2001) }\end{array}$ \\
\hline $\begin{array}{c}\text { Stratospheric } \\
\text { depletion }\end{array}$ & $\mathrm{Kg}$ eq $\mathrm{CFC}$ & $\begin{array}{l}\text { Impact-oriented characterisation } \\
\text { 2001) }\end{array}$ \\
\hline Photochemical oxidation & $\begin{array}{l}\mathrm{Kg} \quad \mathrm{eq} \\
\text { ethylene }\end{array}$ & $\begin{array}{l}\text { Impact-oriented characterisation } \\
\text { 2001) }\end{array}$ \\
\hline
\end{tabular}


In Ecoinvent database there is no detailed process related to CFRP plate. In fact, precise data regarding composite materials is scarce and LCA has rarely been employed to assess FRP reinforcement of steel structures. An adapted process developed in a research work [33] was used herein as described in Table 9. Shouldmore representative data be obtained in the near future, the methodology to be applied would be the same, but the results of the calculations of impact indicators at material scale would be updated.

Table 9. CFRP process (kg) [35].

\begin{tabular}{|c|c|c|c|}
\hline Process & Quantity & Unit & Ecoinvent process \\
\hline Polyacrylonitrile & 1 & kg & polyacrylonitrile \\
\hline $\begin{array}{l}\text { Acrylonytrile from Sohio process, } \\
\text { at plant }\end{array}$ & 1.053 & $\mathrm{~kg}$ & Acrylonitrile \\
\hline Electricity mix & 3.04 & MJ & Electricity, low voltage, FR \\
\hline $\begin{array}{l}\text { Heat, natural gas, at industrial } \\
\text { furnace }>100 \mathrm{~kW}\end{array}$ & 10.5 & MJ & Blast furnace gas, FR \\
\hline
\end{tabular}

\begin{tabular}{llll}
\hline Carbon fiber & $\mathbf{1}$ & $\mathbf{k g}$ & Carbon fiber \\
\hline polyacrylonitrile & 2.08 & $\mathrm{~kg}$ & polyacrylonitrile \\
\hline Electricity mix & 79.2 & MJ & Electricity, low voltage, FR \\
\hline $\begin{array}{l}\text { Heat, natural gas, at industrial } \\
\text { furnace }>100 \mathrm{~kW}\end{array}$ & 97.49 & $\mathrm{MJ}$ & Blast furnace gas, FR \\
\hline
\end{tabular}

\begin{tabular}{|c|c|c|c|}
\hline Composite & 1 & kg & Composite \\
\hline Acetone, liquid at plant & 0.4095 & $\mathrm{~kg}$ & Acetone, liquid, RER \\
\hline $\begin{array}{l}\text { Disposal, inert material, } 0 \% \text { water, } \\
\text { to sanitary landfill }\end{array}$ & 0.076 & $\mathrm{~kg}$ & Inert waste for final disposal, GLO \\
\hline Electricity mix & 47.6 & MJ & Electricity, low voltage, FR \\
\hline Epoxy resin, liquid at plant & 0.404 & $\mathrm{~kg}$ & Epoxy resin, liquid, RER \\
\hline EUR flat pallet & 0.003 & item & EUR flat pallet, RER \\
\hline
\end{tabular}




\begin{tabular}{llllll}
\hline Carbon fiber & 0.872 & $\mathrm{~kg}$ & Carbon fiber \\
\hline $\begin{array}{l}\text { Transport, lorry>32t, EURO4 } \\
\text { Transport, municipal }\end{array}$ & waste & 0.047 & t.km & $\begin{array}{c}\text { Transport, freight, lorry }>32 \mathrm{t}, \\
\text { EURO4, RER }\end{array}$ & \\
\begin{tabular}{l} 
collection, lorry 21t \\
\hline
\end{tabular} & & t.km & $\begin{array}{c}\text { Municipal waste collection service } \\
\text { by 21 metric ton lorry, GLO }\end{array}$ \\
\hline
\end{tabular}

Table 10 presents the environmental results obtained for 1 meter of the adopted adhesively bonded CFRP solution for a $14 \%, 30 \%$ and $46 \%$ life cycle increase.Similar tables are provided for the two other solutions (welded and bolted steel plates in Tables 11 and 12, respectively). These results have been obtained using environmental data from Ecoinvent database with the assumptions described in section 2.1 and listed in Table 1. In particular, electrogen group is considered to have a consumption of 81 /hour, the diesel welder of $4,51 /$ hour and the sander of $301 /$ hour as the crane. Also, human factors such as crew type and workmanship in Table 1 are not taken into account in LCA calculation.

Table 10. Environmental impacts for $1 \mathrm{~m}$ of adhesively bonded CFRP.

\begin{tabular}{|c|c|c|c|c|}
\hline Indicator impact & Unit & $14 \%$ & $30 \%$ & $46 \%$ \\
\hline Acidification potential & $\mathrm{Kg}$ eq $\mathrm{SO}_{2}$ & 0.30 & 0.39 & 0.49 \\
\hline Climate change & $\mathrm{Kg}$ eq $\mathrm{CO}_{2}$ & 39.44 & 57.52 & 75.59 \\
\hline Depletion of abiotic resources & $\mathrm{Kg}$ eq $\mathrm{Sb}$ & 0.32 & 0.49 & 0.67 \\
\hline Dangerous wastes & $\mathrm{kg}$ & 0.41 & 0.65 & 0.90 \\
\hline Non dangerous wastes & $\mathrm{kg}$ & 3.56 & 5.90 & 8.23 \\
\hline Eutrophication & $\mathrm{kg}$ eq $\mathrm{PO}_{4}^{3-}$ & 0.069 & 0.104 & 0.138 \\
\hline Non renewable energy & MJ & 590.35 & 1143.25 & 1696.14 \\
\hline Photochemical oxydation & kg eq ethylene & 0.008 & 0.011 & 0.015 \\
\hline Radioactive waste & $\mathrm{kg}$ & 0.007 & 0.012 & 0.017 \\
\hline Renewable energy & MJ & 22.72 & 43.72 & 64.72 \\
\hline Stratospheric ozone depletion & Kg eq CFC-11- & 0.00001 & $1.1 \mathrm{E}-05$ & $1.5 \mathrm{E}-05$ \\
\hline
\end{tabular}

Table 11. Environmental impacts for $1 \mathrm{~kg}$ of welded structure.

\begin{tabular}{lllll}
\hline Indicator impact & Unit & $14 \%$ & $30 \%$ & $46 \%$ \\
\hline
\end{tabular}




\begin{tabular}{|c|c|c|c|c|}
\hline Acidification potential & $\mathrm{Kg}$ eq $\mathrm{SO}_{2}$ & 0.07 & 0.14 & 0.22 \\
\hline Climate change & $\mathrm{Kg}$ eq $\mathrm{CO}_{2}$ & 15.44 & 30.89 & 46.34 \\
\hline Depletion of abiotic resources & $\mathrm{Kg}$ eq $\mathrm{Sb}$ & 0.089 & 0.178 & 0.267 \\
\hline Dangerous wastes & $\mathrm{kg}$ & 3.63 & 7.27 & 10.91 \\
\hline Non dangerous wastes & $\mathrm{kg}$ & 13.52 & 27.04 & 40.56 \\
\hline Eutrophication & $\mathrm{kg}$ eq $\mathrm{PO}_{4}^{3-}$ & 0.017 & 0.035 & 0.052 \\
\hline Non renewable energy & MJ & 128.77 & 257.55 & 386.33 \\
\hline Photochemical oxydation & kg eq ethylene & 0.007 & 0.014 & 0.021 \\
\hline Radioactive waste & $\mathrm{kg}$ & 0.0004 & 0.0008 & 0.0012 \\
\hline Renewable energy & MJ & 13.57 & 27.14 & 40.71 \\
\hline Stratospheric ozone depletion & Kg eq CFC-11- & 0.00000 & $1.7 \mathrm{E}-06$ & $2.6 \mathrm{E}-06$ \\
\hline
\end{tabular}

Table 12. Environmental impacts for $1 \mathrm{~kg}$ of bolted structure.

\begin{tabular}{lllll}
\hline Indicator impact & Unit & $14 \%$ & $30 \%$ & $46 \%$ \\
\hline Acidification potential & $\mathrm{Kg} \mathrm{eq} \mathrm{SO}_{2}$ & 0.14 & 0.28 & 0.42 \\
\hline Climate change & $\mathrm{Kg} \mathrm{eq} \mathrm{CO}_{2}$ & 22.33 & 44.66 & 66.99 \\
\hline Depletion of abiotic resources & $\mathrm{Kg} \mathrm{eq} \mathrm{Sb}$ & 0.13 & 0.27 & 0.40 \\
\hline Dangerous wastes & $\mathrm{kg}$ & 3.69 & 7.38 & 11.07 \\
\hline Non dangerous wastes & $\mathrm{kg}$ & 13.91 & 27.83 & 41.75 \\
\hline Eutrophication & $\mathrm{kg} \mathrm{eq} \mathrm{PO}_{4}{ }^{3-}$ & 0.028 & 0.057 & 0.086 \\
\hline Non renewable energy & $\mathrm{MJ}$ & 140.84 & 281.68 & 422.52 \\
\hline Photochemical oxydation & $\mathrm{kg}$ eq ethylene & 0.008 & 0.017 & 0.025 \\
\hline Radioactive waste & $\mathrm{kg}$ & 0.001 & 0.002 & 0.003 \\
\hline Renewable energy & $\mathrm{MJ}$ & 14.12 & 28.25 & 42.38 \\
\hline Stratospheric ozone depletion & $\mathrm{Kg}$ eq CFC-11- & 0.00000 & $4 \mathrm{E}-06$ & $6 \mathrm{E}-06$ \\
\hline
\end{tabular}

For the sake of clarity when comparing the different strengthening solutions, Figure 13 only focuses on the climate change. Concerning adhesively bonded CFRP and under the assumptions of this study, climate change impact has been the most important in all cases. Detailed results for other environmental impacts are given in Tables 10, 11, 12. 


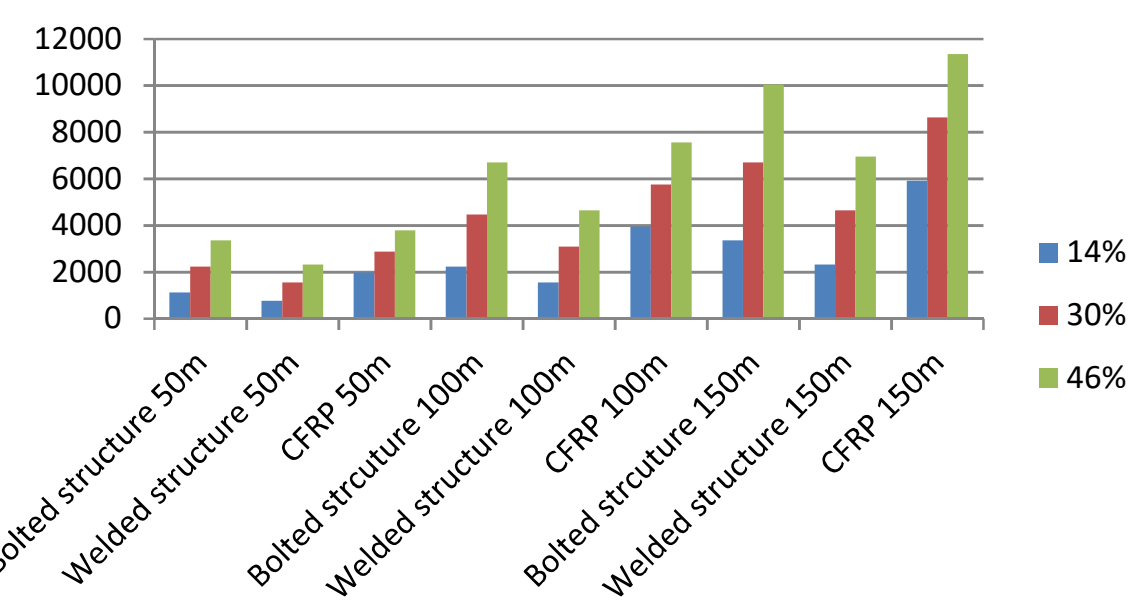

Fig. 13. Climate change in $\mathrm{kg}$ eq $\mathrm{CO} 2$ for each solution of reinforcement while repairing $50 \mathrm{~m}$, $100 \mathrm{~m}$ or $150 \mathrm{~m}$.

The use of adhesively bonded CFRP during the maintenance operation of the bridge implies less traffic interruption and so less traffic congestion. As a first approximation, one calculates the variation of emission of $\mathrm{NOx}$ (nitrogen oxide), $\mathrm{CO}$ (carbon monoxide) and $\mathrm{HC}$ (hydrocarbons). These gases are controlled in Europe because they are extremely harmful as they carry fine particles. They have an impact on acidification potential and eutrophication potential that are assessed herein. The same assumptions as those in section 4.4 (and detailed in Table 6) are considered. As in section 4.4, 12 days of works are needed for welded and bolted steel plates and 5 days of works for adhesively bonded CFRP. Figure 14 shows the results obtained in terms of impact indicators on acidification potential and eutrophication comparing 12 days of works to 5 days (solution with adhesively bonded CFRP).

(a) 


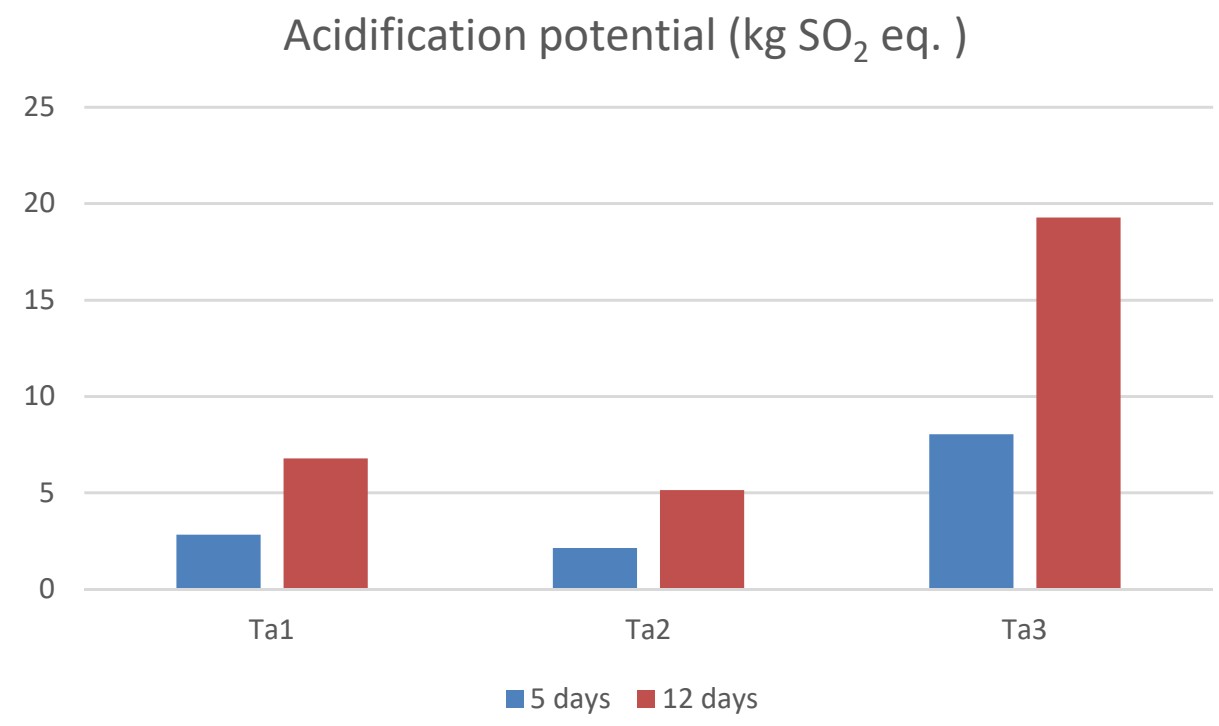

(b)

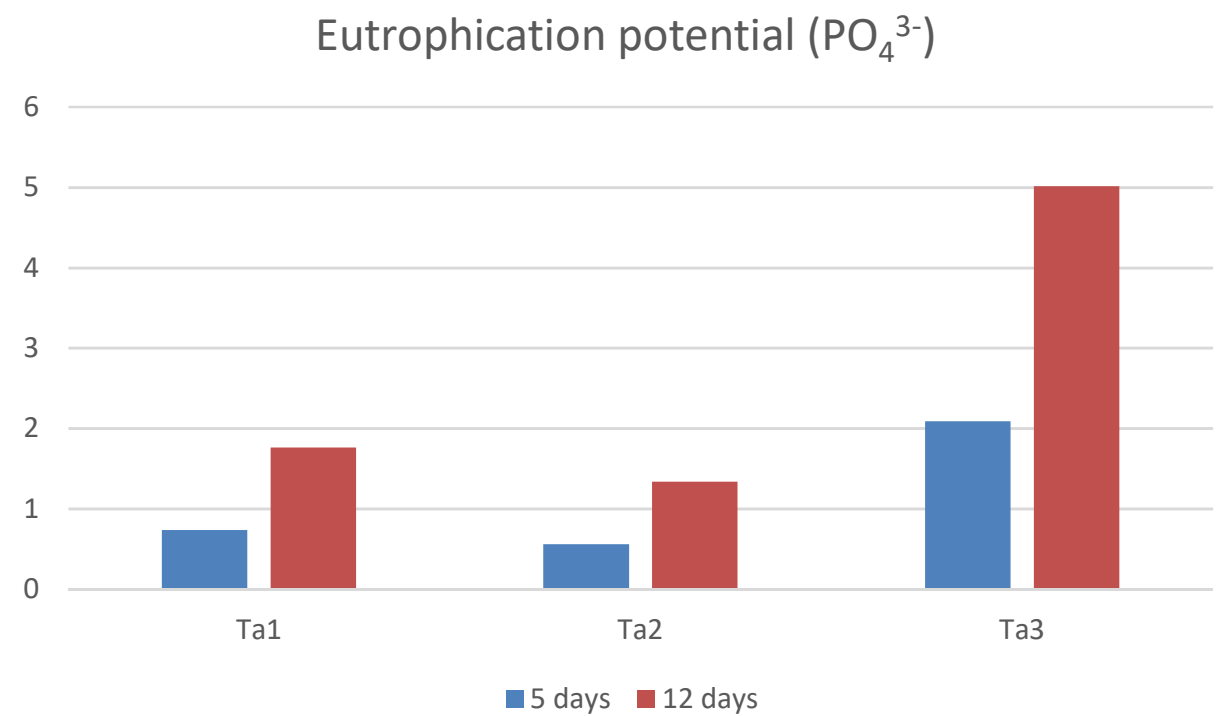

Fig. 14. (a) Acidification potential and (b) eutrophication potential for $\mathrm{Ta}_{1}, \mathrm{Ta}_{2}$ and $\mathrm{Ta}_{3}$ comparing the work duration (12 days are needed for welded and bolted steel plates and 5 days for adhesively bonded CFRP).

Obtained results need further development and should be considered carefully as some factors have not been taken into account (e.g. the roads gradient and the state and the age of the road surface) and as only two types of vehicle have been used (cars and trucks) to perform the calculation. Such results enable to identify the fact that the CFRP solution leads to lower traffic disruption, which induces less emissions and then less acidification potential and eutrophication (other impact indicators remaining similar). Such environmental impacts can be considered in parallel to those previously shown in Tables 10,11 and 12 . 


\section{CONCLUSIONS}

This paper proposes a global framework including economic, social and environmental analyses for highlighting the benefits of different strategies for fatigue strengthening. The aim is to gather precise information on unit costs/environmental data to compare traditional strengthening methods (use of welded and bolted steel plates) with a more recent repair technique (use of adhesively bonded CFRP).

Direct costs include the cost of the strengthening action for the bridge owner and the corresponding impact on the end of the service life. It therefore takes into account the effective year for decommissioning/reconstruction.

Indirect costs are assumed to be the user costs in case of maintenance works. These costs include traffic delay, vehicle operating and accident costs, calculated herein with the model QUEWZ-98.

Environmental impacts are assessed by considering not only the materials used in the strengthening process, but also indirect consequences due to traffic disruptions.

Though, the general framework is highly dependent on input parameters, it enables the comparison of several strengthening strategies. It is thus shown how several parameters can significantly influence the comparison results (such as yearly discount rate of money, costs of maintenance works, area of the bridge deck concerned by strengthening, end-of-life costs, traffic configuration...). Additionaly, it enables the determination of several cases where adhesively bonded CFRP can be an interesting solution. In particular, such a model shows how higher initial costs of CFRP can be offset in some specific cases thanks to reduced labor, reduced construction time, and reduced traffic disruptions during construction.

To improve the proposed life-cycle framework, some aspects could be further considered as mentioned below:

- for the welded option, it would be interesting to analyze the implications of welding on site (exposed to the climate conditions) and the quality control (time, cost, risk of having to repair),

- for the bolted option, one could analyze the complexity of executing a bolted reinforcement to an element, joint or detail not designed for this purpose,

- for the adhesively bonded CFRP option, one should analyze the necessity of monitoring the bonding and/or behavior of the adhesive, with the implications in inspection and maintenance. The use of such monitoring could allow detecting premature delamination, and replacing the applied reinforcement, 
- In the case of steel bridges older than 50 years, there might be a layer of toxic lead paint to be removed. Often the whole girder or even the bridge, has to be encapsulated during the process of removal of the lead paint in order to make sure there is no lead-paint dust leaking out in the air or water (under the bridge). This complex process is generally required depending on the national or international guidelines, which might change the benefits of the analysis.

The impact assessment stage of economic, environmental, and societal categories was made separately for each criterion although based on the same assumptions. The following step, the combination of criteria, depends on the aim of the analysis. On the one hand, if the goal is to identify the improvement possibilities of the processes contributing with major impacts, then the structural, environmental and costs performances may be interpreted individually. On the other hand, if the goal is to help in a decision making problem, then the balance between the individual performances may be achieved by a multicriteria decision analysis. A life-cycle analysis is not a decision making approach. However, it can provide valuable information for stakeholders in the process of decision making.

Further research actions could also analyze the effect of uncertainties on some parameters and lead an optimization problem to minimize both one objective and multi-objective functions aiming at simultaneously minimizing several impacts (e.g. economic and environmental impacts, as highlighted for example in [36] or [37]).

Experience shows that the use of higher cost materials and methods can be very effective if they allow the repair work to be carried out with minimal or zero interruption to traffic flow, especially on bridges with intensive heavy transport circulation. For this reason, it can be stated that bridges are major structures for which decisions are dominated by traffic and commercial considerations much more than by the basic cost of executing the structural repair. These considerations are measured for each situation due to the dynamic nature of the indicators (importance of the bridge, number of users, existence of alternatives, etc.).

\section{ACKNOWLEDGMENTS}

The authors wish to acknowledge the contribution of Epsilon Composites to the project and Europe. This project has indeed received funding from the European Union's Seventh Framework Programme for research, technological development and demonstration under grant agreement no 31109806.0008. FASSTbridge is co-funded by Funding Partners of the ERANET Plus Infravation and the European Commission. The Funding Partners of the Infravation 2014 Call are: Ministerie van Infrastructuur en Milieu, Rijkswaterstaat; Bundesministerium für 
Verkehr, Bau und Stadtentwicklung; Danish Road Directorate; Statens Vegvesen Vegdirektoratet; Trafikverket-trv; Vegagerðin; Ministere de l'Écologie, du Developpement Durable et de l'Énergie; Centro para el Desarrollo Tecnologico Industrial; Anas s.p.a.; Netivei, Israel - National Transport Infrastructure Company LTD; Federal Highway Administration USDOT. The authors thank the partners of this project for providing unitary data that were used in LCC and LCA. The opinions and conclusions presented in this paper are those of the writers and do not necessarily reflect the views of the sponsoring organizations.

\section{REFERENCES}

[1] X. L. Zhao et L. Zhang, «State-of-the-art review on FRP strengthened steel structures,» Engineering Structures, vol. 29 (8), p. 1808-1823, 2007.

[2] D. Linghoff, R. Haghani et M. Al-Emrani, «Carbon-fibre composites for strengthening steel structures,» Thin-walled structures, vol. 47 (10), p. 144-152, 2009.

[3] D. Schnerch, M. Dawood, S. Rizkalla et E. Sumner, «Proposed design guidelines for strengthening of steel bridges with FRP materials,» Construction and Building Materials, vol. 21, n% \%15, pp. 1001-1010, 2007.

[4] X. L. Zhao, FRP-strengthened metallic structures, CRC Press, 2013.

[5] P. Colombi et G. Fava, «Fatigue crack growth in steel beams strengthened by CFRP strips,» Theoretical applied fracture mechanics, vol. 85, pp. 173-182, 2016.

[6] E. Lepretre, S. Chataigner, L. Dieng et L. Gaillet, «Reinforcement of a cracked steel plate using CFRP bonding,» chez In: Proceedings of RILEM - MCD, Nantes, 2016.

[7] A. Hosseini, E. Ghafoori, M. Motavalli, A. Nussbaumer et X. Zhao, «Mode I fatigue crack arrest in tensile steel members using prestressed CFRP plates,» Composite structures, vol. 178, pp. 119-134, 2017.

[8] M. Tavakkolizadeh et S. H., «Fatigue strength of steel girders strengthened with carbon fiber reinforced polymer patch,» Journal of Structural Engineering, vol. 129, n% \%12, pp. 186-196, 2003.

[9] B. Täljsten, C. Hansen et S. J.W., «Strengthening of old metallic structures in fatigue with prestressed and non-prestressed CFRP laminates,» Construction and Building Materials, vol. 23, n%14, pp. 1665-1677, 2009. 
[10] E. Ghafoori, M. Motavalli, X. Zhao, A. Nussbaumer et M. Fontana, «Fatigue design criteria for strengthening metallic beams with bonded CFRP plates,» Engineering Structures, vol. 101, pp. 542-557, 2015.

[11] A. Hosseini, E. Ghafoori, R. Al-Mahaidi, X. Zhao et M. M., «Strengthening of a 19thcentury roadway metallic bridge using nonprestressed bonded and prestressed unbonded CFRP plates,» Construction and Building Materials, vol. 209, pp. 240-259, 2019.

[12] M. Wabeh, R. Boundouki, S. Chataigner, K. Benzarti, G. Gemignanin, M. Zalbide, D. Garcia-Sanchez, V. Birtel, F. Lehmann, M. Fischer, E. Martin et L. Sopena, «Preventive fatigue strengthening of steel structures with adhesively bonded CFRPs - Efficiency demonstration on a real bridge,» Journal of Composites for construction, Under Review.

[13] E. Ghafoori, M. Motavalli, A. Nussbaumer, A. Herwig, G.S. Prinz, M. Fontana, «Design criterion for fatigue strengthening of riveted beams in a 120 -year-old railway metallic bridge using pre-stressed CFRP plates,» Composites: Part B, vol. 68, pp. 1-13, 2015.

[14] E. Ghafoori, A. Hosseini, R. Al-Mahaidi, X.L. Zhao, M. Motavalli, «Prestressed strengthening and long term wireless monitoring of an old roadway metallic bridge,» Engineering Structures, vol. 176, pp. 585-605, 2018.

[15] «NCHRP 503. Application of Fiber Reinforced Polymer Composites to the Highway Infrastructure,» NCHRP REPORT 503, ISBN 0-309-08769-4, 2003.

[16] A. Orcesi, A. Feraille et S. Chataigner, «A life cycle analysis approach applied to the strenghtening of steel bridges,» chez The 9th International Conference on FibreReinforced Polymer (FRP) Composites in Civil Engineering (CICE 2018), Paris, 2018.

[17] A. Orcesi, A. Feraille et C. S., «A life-cycle analysis approach applied to the strengthening of the Jarama steel Bridge,» chez IABSE 2018, Nantes, 2018.

[18] FASSTbridge, «Deliverable D4.5. Cost-benefit analysis plan,» 2017.

[19] FASSTbridge, «Deliverable D4.6. Draft Life Cycle Analysis,» 2017.

[20] S. Chataigner, K. Benzarti, G. Foret, J. Caron, G. Gemignani, M. Brugiolo, I. Calderon, I. Pinero, V. Birtel et F. Lehmann, «Design and evaluation of an externally bonded CFRP reinforcement for the fatigue reinforcement of old steel structures,» Engineering Structures, vol. 177, pp. 556-565, 2018.

[21] FASSTbridge, «Deliverable D5.5. FASSTbridge technical, environmental and cost benefit report - Study case,» 2018. 
[22] EN 1993-1-9- Eurocode 3. Design of steel structures. Part1-9: Fatigue strength of steel structures, Bruxelles: European Committee for Standalization (CEN).

[23] ISO 15686-5. Standardized method of life cycle costing for construction, 2008.

[24] C. Cremona, Structural performance: Probability-based assessment, Wiley \& Sons, inc. , 2011.

[25] R. Benekohal, H. Ramezani et K. Avrenli, «Queue and user's costs in highway work zones,» Urbana, (10). Available at: http://ict.illinois.edu/publications/report files/FHWA-ICT-10-075.pdf., 2010.

[26] L. Copeland, «User's manual for QUEWZ-98.,» Research Report 1745-2, Texas Transportation Institute, College Station, TX., 1998.

[27] K. Huen, «Evaluation of Work Zone Strategies and User Delay Costs Associated with Strategies and Treatments, $\gg$ chez In Annual Conference of the Transportation Association of Canada, Charlottetown, PEI., 2006.

[28] H. Salokangas, «ETSI PROJECT (STAGE II), Bridge Life Cycle Optimisation,» Helsinki University of Technology Publications in Bridge Engineering, TKK-R-BE3, Espoo., 2009.

[29] N.-B. Ta, A. Orcesi et C. C., «A comparative life-cycle cost analysis of steel-concrete composite bridges,» chez IALCCE'12, Vienna, 2012.

[30] N.-B. Ta, A. Orcesi et C. Cremona, «A holistic approach for analyzing bridges crossing a highway,» chez ICOSSAR 2013, New York, 2013.

[31] C. Kaur Anand et B. Amor, «Recent developments, future challenges and new research directions in LCA of buildings: A critical review,» Renewable and Sustainable Energy Reviews, vol. 67, pp. 408-416, 2017.

[32] ISO 14040. Management environnemental - Analyse du Cycle de Vie - Principes et cadre., International Organisation for Standardization, 2006.

[33] ISO 14044. Management environnemental - Analyse du Cycle de Vie - Exigences et lignes directrices., 2006.

[34] «NF EN $15804+$ A1. Contribution des ouvrages de construction au développement durable - Déclarations environnementales sur les produits - Règles régissant les catégories de produits de construction,» 2014. 
[35] G. Herfray et A. Feraille, «Inventaire de Cycle de Vie des matériaux composites,» Rapport de la chaire Bouygues "Bâtir durable \& innover", 2013.

[36] C. Tapia et J. Padgett, «Multi-objective optimisation of bridge retrofit and post-event repair selection to enhance sustainability,» Structure and Infrastructure Engineering, vol. 12 (1), p. 93-107, 2016.

[37] A. Orcesi, D. Frangopol et S. Kim, «Optimization of bridge maintenance strategies based on multiple limit states and monitoring,» Engineering Structures, vol. 32 (3), pp. 627-640, 2010. 